\title{
Endovascular Treatment of Posterior Cerebral Artery Trunk Aneurysm: The Status Quo and Dilemma
}

\author{
Kun $\mathrm{Hou}^{1+}$, Xianli $\mathrm{Lv}^{2+}$ and Jinlu Yu${ }^{1 *}$ \\ ${ }^{1}$ Department of Neurosurgery, First Hospital of Jilin University, Changchun, China, ${ }^{2}$ Department of Neurosurgery, Beijing \\ Tsinghua Changgung Hospital, School of Clinical Medicine, Tsinghua University, Beijing, China
}

OPEN ACCESS

Edited by:

Atilla Ozcan Ozdemir,

Eskişehir Osmangazi University, Turkey

Reviewed by:

Luis Rafael Moscote-Salazar, Latinamerican Council of Neurocritical

Care (CLaNi), Colombia

Jian Liu,

Capital Medical University, China

${ }^{*}$ Correspondence:

Jinlu Yu

jlyu@jlu.edu.cn

orcid.org/0000-0003-2329-7946

tThese authors share first authorship

Specialty section:

This article was submitted to Endovascular and Interventional

Neurology,

a section of the journal

Frontiers in Neurology

Received: 24 July 2021 Accepted: 08 December 2021

Published: 06 January 2022

Citation:

Hou K, Lv X and Yu J (2022) Endovascular Treatment of Posterior Cerebral Artery Trunk Aneurysm: The

Status Quo and Dilemma.

Front. Neurol. 12:746525.

doi: 10.3389/fneur.2021.746525
The posterior cerebral artery (PCA) is an important artery that can be divided into four segments (P1-4): segments P1-2 are proximal segments, and segments P3-4 are distal segments. Various aneurysms can occur along the PCA trunk. True saccular aneurysms are rare, and most PCA trunk aneurysms are dissecting. Sometimes, the PCA trunk can give rise to flow-related aneurysms in association with high-flow arteriovenous shunt diseases or moyamoya disease and internal carotid artery occlusion. Some PCA trunk aneurysms require treatment, especially ruptured or large/giant aneurysms. Recently, endovascular treatment (EVT) has become the mainstream treatment for PCA trunk aneurysms, and it mainly involves reconstructive or deconstructive techniques. Traditional EVT includes selective coiling with/without stent or balloon assistance and parent artery occlusion (PAO). For proximal aneurysms, the PCA should be preserved. For distal aneurysms, PAO can be performed. However, during EVT, preservation of the PCA must naturally be the prime objective. Recently, flow-diverting stents have been used and are a revolutionary treatment for unruptured dissecting aneurysms of the PCA trunk. Despite the associated complications, EVT remains an effective method for treating PCA trunk aneurysms and can result in a good prognosis.

Keywords: posterior cerebral artery, trunk, aneurysm, endovascular treatment, review

\section{INTRODUCTION}

The posterior cerebral artery (PCA) is a very important pial artery; commonly, it arises from the basilar artery (BA), and uncommonly, it arises from the posterior communicating artery (PcomA) $(1,2)$. Similar to other pial arteries, the PCA region is susceptible to aneurysms, accounting for $0.7-2.2 \%$ of all intracranial aneurysms and $7-15 \%$ of all vertebrobasilar aneurysms $(3,4)$. Of the aneurysms in the PCA region, those limited to the PCA trunk are uncommon; moreover, the management of these aneurysms is difficult and complex.

Compared with aneurysms located in other areas, PCA trunk aneurysms are more frequently dissecting, presenting with fusiform, giant (even bilateral), and even serpentine and dolichoectatic shapes (5-9). A fusiform aneurysm shape can be found in up to $25 \%$ of all PCA trunk aneurysms (10). PCA trunk aneurysms can occur in isolation or in association with brain arteriovenous malformation (BAVM), dural or pial arteriovenous fistula (DAVF or PAVF), vein of Galen aneurysmal malformation, internal carotid artery (ICA) occlusion, and moyamoya disease (MMD) (11-16).

The spontaneous disappearance of PCA trunk aneurysms due to thrombosis is rare (17). They often harbor insufficient organized thrombi and are prone to hemorrhage, and intervention is 
necessary, especially for ruptured aneurysms (18). PCA trunk aneurysms are challenging for surgical treatment and can cause serious complications because the PCA region harbors perforating arteries, deep venous structures and cranial nerves $(19,20)$. Currently, endovascular treatment (EVT) has become the mainstream option for intracranial aneurysm treatment, especially EVT involving flow-diverting stents (FDSs) (21). This choice is good for PCA trunk aneurysms, especially nonmass-compressing, non-giant aneurysms (22). Until now, the understanding of EVT for PCA trunk aneurysm treatment has been insufficient. Therefore, we performed this review.

\section{PCA TRUNK ANATOMY}

Embryologically, PCA arises from the ICA, but at birth, its most frequent origin is from the $\operatorname{BA}(23,24)$. When the PCA originates directly from the PcomA, it is called a fetal-type PCA, with an occurrence rate of 3 to $36 \%$ (5). In fetal-type PCA, the PCA before the PcomA can be hypoplastic or absent, and the PcomA features the same diameter as or a larger diameter than the PCA (2). The PCA trunk can exhibit aplasia, hypoplasia, duplication, fenestration and other abnormalities (25-28).

Zeal and Rhoton et al. divided the PCA into four segments: the precommunicating segment (P1), ambient segment (P2), quadrigeminal segment (P3), and calcarine segment (P4). The $\mathrm{P} 2$ segment is long and further divided into anterior (P2A) and posterior $(\mathrm{P} 2 \mathrm{P})$ parts $(29,30)$. In the $\mathrm{Uz}$ study, the P2A and $\mathrm{P} 2 \mathrm{P}$ parts were classified as two separated segments, so P1-P5 segmentation was adopted (31). Currently, P1-P4 segmentation is popular.

The PCA can be divided into proximal and distal segments (32). P1 and P2 in the Zeal and Rhoton et al. study or P1-P3 in the Uz study belong to the proximal segment. PCA diameter and length are important for EVT. In anatomical studies, the proximal PCA mean diameter was approximately $2 \mathrm{~mm}$, the distal PCA diameter at the origin was approximately $1.5 \mathrm{~mm}$, and the proximal length was approximately $5 \mathrm{~cm}(31,33)$. The PCA segmentations are shown in Figure 1.

The PCA gives rise to three types of branches: central perforating branches, ventricular branches (medial and lateral posterior choroidal arteries often arise from the P2 segment), and cerebral branches to the cortex and corpus callosum splenium $(29,34)$. In perforating branches, the P1 segment sends out important thalamoperforating arteries, short/long circumflex arteries and occasionally medial posterior choroidal arteries (35).

The PCA has anastomotic collaterals between the lateral posterior choroidal artery of the P2 segment and the anterior choroidal artery, between the long circumflex arteries of the P1 segment and the superior cerebellar artery at the level of the quadrigeminal plate, between the splenial artery of the P3P4 segment and the posterior pericallosal artery of the anterior cerebral artery, and between the inferior temporal branch of the PCA and the superior temporal branches of the middle cerebral artery (4).

\section{CLASSIFICATIONS OF PCA TRUNK ANEURYSMS}

\section{Saccular Bifurcation or Dissecting Aneurysms}

Saccular bifurcation aneurysms, which are true aneurysms, are rare, generally arise as a result of hemodynamic stress and result from stretching and outpouching of all of the layers of the arterial wall at the branch origin or in the fenestration of the PCA (Figure 2A) (28, 36-38). Aneurysms unrelated to the branching zone seem more likely to result from arterial dissection (Figure 2B) (38-40). Approximately 80-90\% of PCA trunk aneurysms are dissecting $(38,41,42)$.

PCA trunk dissecting aneurysms can be unstable, and they can grow with extension and dilatation (8). Progressive thrombosis is not uncommon in PCA trunk aneurysm growth and results in serpentine aneurysms, in which there is a twisted nonendothelialized channel of vascular course within the thrombus, accounting for $18 \%$ of all intracranial serpentine aneurysms (Figure 2C) $(43,44)$.

\section{Proximal and Distal Aneurysms}

Aneurysms can be divided into proximal and distal types. Those of the P1-P2 segment were proximal aneurysms (Figures 2D,E), and those of the P3-P4 segment were distal aneurysms. This classification is important because the P1-P2 segment has important perforating arteries, and EVT must be performed more carefully (45).

For PCA trunk aneurysms, proximal aneurysms are more common (46). For instance, in a report by Ciceri et al., proximal PCA aneurysms accounted for $81 \%$ of cases (4). Specifically, in a report by Ferrante et al., PCA trunk aneurysms were localized on $\mathrm{P} 1$ in $22.6 \%$ of cases, the P1-P2 junction in $12 \%$ of cases, P2 in $46.7 \%$ of cases, and P3 in $18.6 \%$ of cases (6). In a report by Park et al., PCA-dissecting aneurysms involved P1 in $19.0 \%$ of cases, P1-2 junctions in $14.3 \%$ of cases, P2 in $47.7 \%$ of cases and P2-3 junctions in $9.0 \%$ of cases (38).

\section{Flow-Related Aneurysms}

In the pathological state, PCAs can have increased blood flow, which will result in aneurysms on the PCA trunk, called flowrelated aneurysms $(47,48)$. In occlusive diseases of the anterior circulation, such as ICA occlusion (Figure 2D), ICA agenesis or MMD (Figure 2F), increased hemodynamic stress through the PCA will lead to PCA trunk aneurysms, especially in the P1 segment, which is the collateral pathway (49-55).

Arteriovenous shunt diseases, including BAVM, DAVF, PAVF or vein of Galen aneurysmal malformations, can result in blood flow overload (Figures 2G,H) (12, 14-16, 56-60). These aneurysms are often located at the proximal PCA (61).

\section{Other Classifications}

PCA trunk aneurysms can be divided into spontaneous (non-traumatic) or traumatic types $(40,62)$. Risk factors for the spontaneous type include atherosclerosis, vasculitis, inflammation/infection, connective tissue disease and genetic predisposition (63-70). Risk factors for the traumatic type 


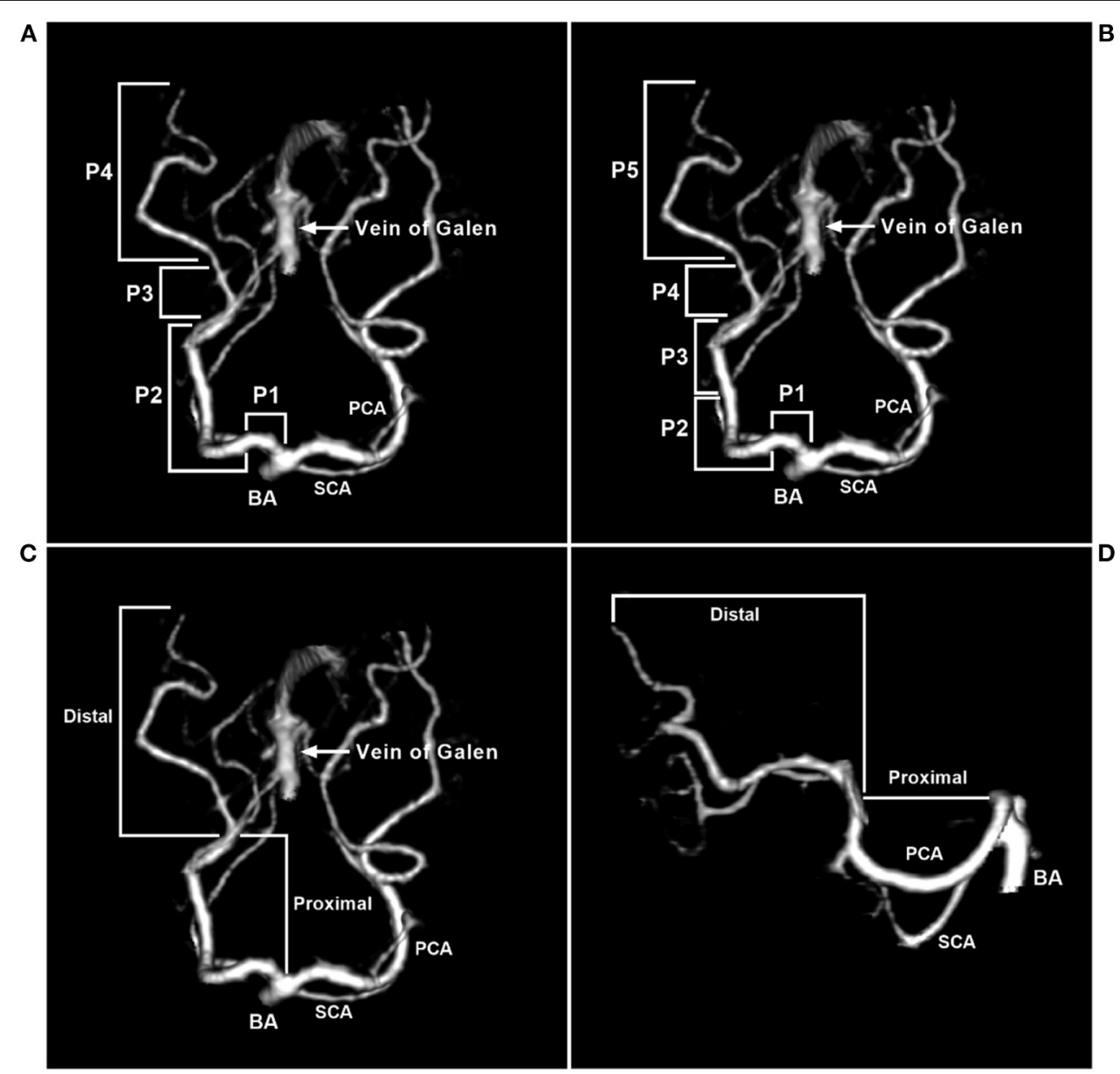

FIGURE 1 | Segmentation of the PCA. (A) CTA of the superior-inferior view showing that the PCA was divided into four segments: P1 (precommunicating segment), P2 (ambient segment), P3 (quadrigeminal segment), and P4 (calcarine segment). P2 was further divided into anterior (P2A) and posterior (P2P) parts. (B) CTA of the superior-inferior view showing that the PCA was divided into five segments. (C,D) CTA of the superior-inferior view (C) and the lateral view (D) showing that the PCA can be divided into proximal and distal segments. BA, basilar artery; CTA, computed tomography angiography; PCA, posterior cerebellar artery; SCA, superior cerebellar artery.

include closed and open injuries because of sudden stretching or compression of the PCA against the tentorium or direct artery disruption by sharp injury, resulting in traumatic aneurysms $(17,71,72)$. Traumatic aneurysms are called pseudoaneurysms with a cavity of encapsulated hematomas communicating with the lumen of the PCA (73).

PCA trunk aneurysms can also be divided into ruptured or unruptured aneurysms; when found, half of PCA trunk aneurysms are ruptured, and most ruptured aneurysms are smaller than $10 \mathrm{~mm}$ and are usually distally located (4, 60, 62, 74). PCA trunk aneurysms are of various sizes; they can be divided into small, large and giant aneurysms, and large and giant aneurysms are common $(3,4,75,76)$. In a report by Ferrante et al., PCA trunk aneurysms were large in $43.6 \%$ of cases, small in $33.3 \%$ of cases, and giant in $23 \%$ of cases (6). Certainly, multiple PCA trunk aneurysms can occur (Figure 3) $(10,60,77)$.

\section{TRADITIONAL EVT STRATEGIES}

There is no standardized strategy for the management of PCA trunk aneurysms. For unruptured dissecting aneurysms, aggressive EVT is not recommended, and conservative management and anticoagulation can be chosen (68). For ruptured PCA trunk aneurysms, aggressive EVT is necessary and includes deconstructive and reconstructive methods, the choice of which depends on the aneurysm morphology and its location. However, for PCA trunk aneurysms, preservation of antegrade flow in the PCA must naturally be the prime objective. Most aneurysms of the PCA trunk are treated via the vertebrobasilar system; however, when the aneurysms are located on the fetal-type PCA trunk, or the vertebrobasilar system is occluded, the approach through the ICA is the only choice (Figure 4). 
A

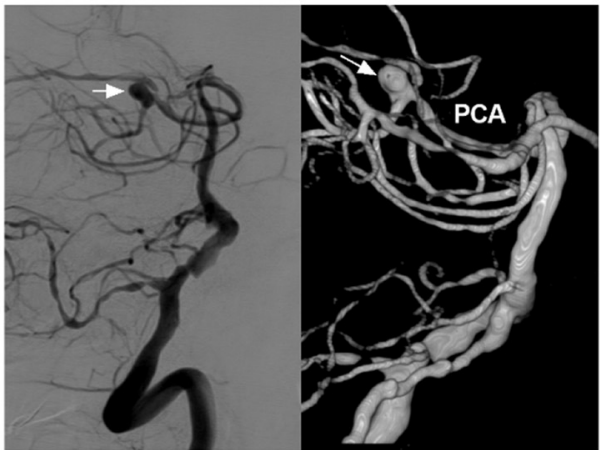

C

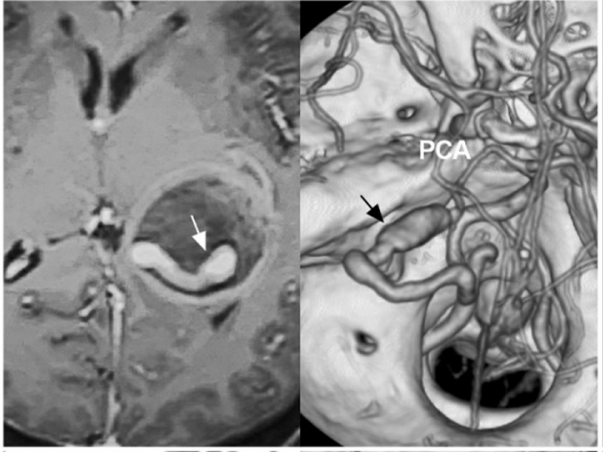

E

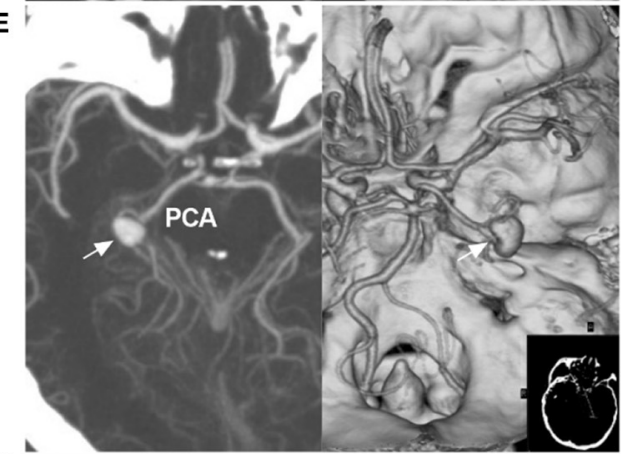

G

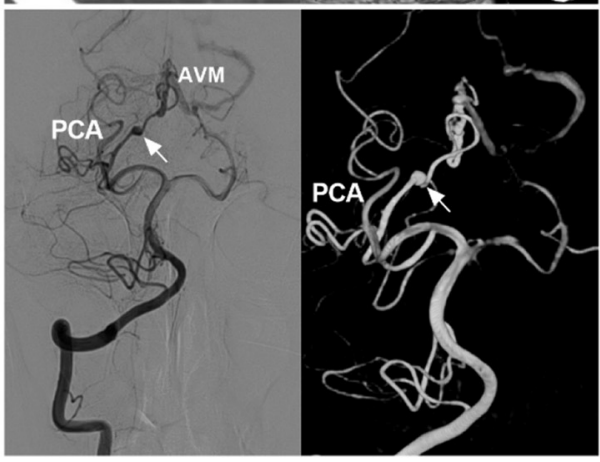

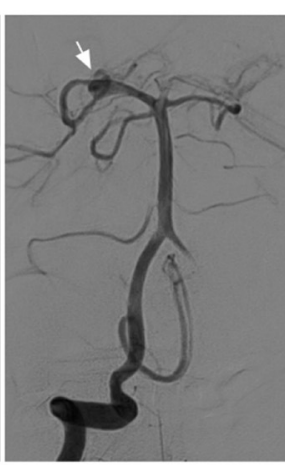
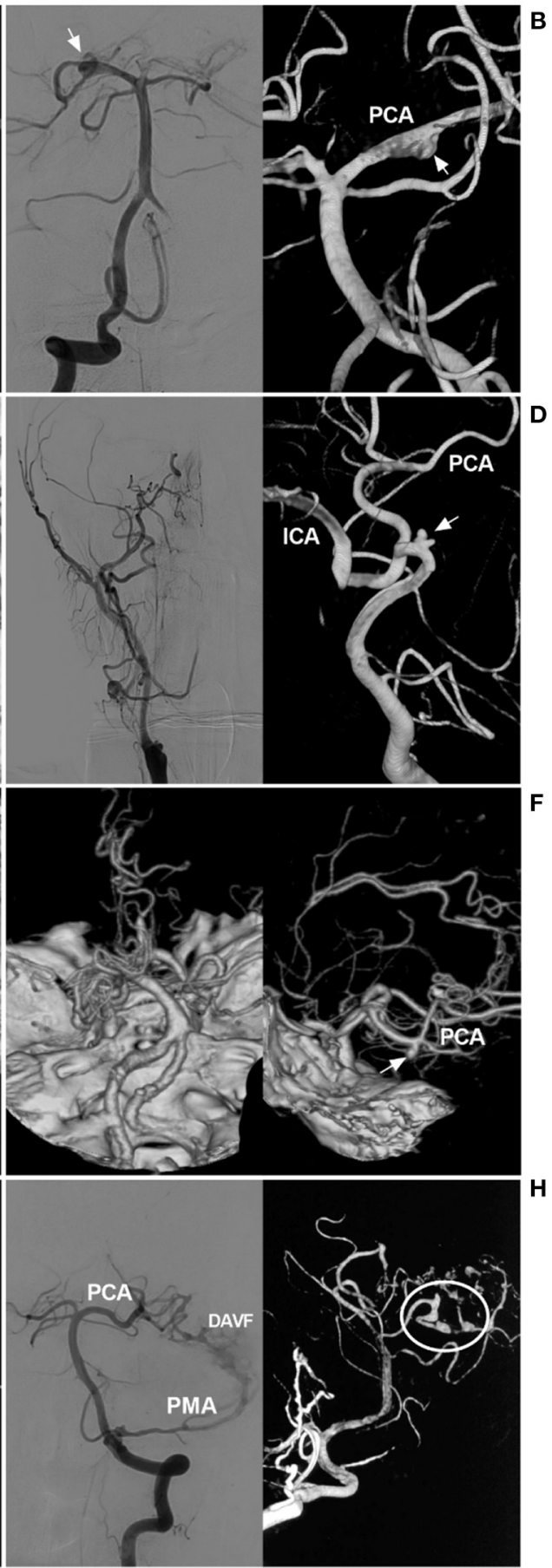

FIGURE 2 | Classification of PCA trunk aneurysms. (A) Angiograms of the VA show a saccular true bifurcation aneurysm (arrows) at the distal segment of the PCA (left, two-dimensional angiogram; right, three-dimensional angiogram). (B) Angiograms of the VA show a dissecting aneurysm (arrows) at the proximal segment of the PCA (left, two-dimensional angiogram; right, three-dimensional angiogram). (C) MRI (left) shows an aneurysm with thrombosis [a tunnel can be seen (arrow)], and CTA (right) confirms a serpentine aneurysm (arrow) of the distal PCA. (D) Angiogram of the carotid artery (left) shows that the ICA was occluded at the beginning; three-dimensional angiogram of the VA (right) shows an aneurysm (arrow) located on the P1 segment, and the PCA supplies the anterior circulation. (E) CTA shows a P2 aneurysm (arrows) (left, maximum intensity projection; right, constructive image). (F) Left, CTA of the superior-inferior view shows occlusion of the bilateral middle cerebral arteries, confirming the moyamoya disease diagnosis; right, CTA of the lateral view shows an aneurysm (arrow) on the distal PCA. (G) Angiograms of the VA show the aneurysm (arrows) on the PCA as the feeding artery for an AVM (left, two-dimensional angiogram; right, three-dimensional angiogram). (H) Angiogram of the VA (left, two-dimensional DSA) shows that the PCA and PMA supply the DAVF; angiogram of the VA (right, three-dimensional angiogram) shows multiple tandem aneurysms (circle) on the PCA. AVM, arteriovenous malformation; CTA, computed tomography angiography; DAVF, dural arteriovenous fistula; ICA, internal carotid artery; MRI, magnetic resonance imaging; PCA, posterior cerebellar artery; PMA, posterior meningeal artery; VA, vertebral artery. 
A
C
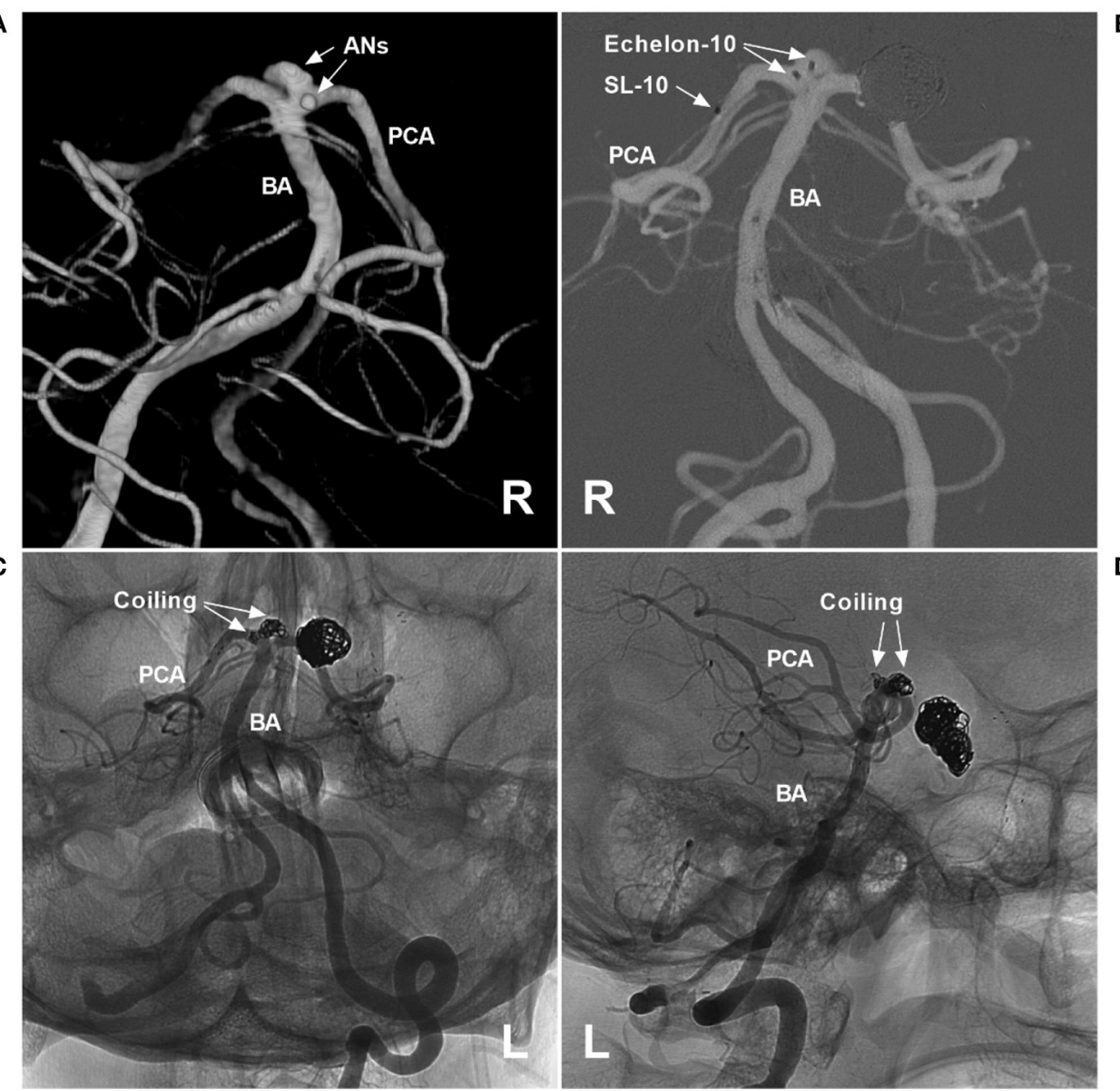

\section{B}

D

FIGURE 3 | Assisted coiling for multiple P1 segment aneurysms. (A) Three-dimensional angiogram of the VA shows two aneurysms (arrows and ANs) on the right P1 segment. (B) Roadmap of the left VA shows two Echelon microcatheters (Medtronic, Irvine, CA, USA) (double arrows) that went into the aneurysms and an SL-10 microcatheter (Stryker Neurovascular, Fremont, CA, USA) (single arrow) past the aneurysms that were ready for stent deployment. (C,D) Unsubtracted DSA of different views shows that two aneurysms were coiled under the Atlas stent's (Stryker Neurovascular, Fremont, CA, USA) assistance. In addition, previous coiling for posterior communicating artery aneurysms can be seen. AN, aneurysm; BA, basilar artery; L, left; PCA, posterior cerebellar artery; R, right; VA, vertebral artery.

\section{Selective Coiling}

Selective coiling with/without stent or balloon assistance is an easy reconstructive method for coiling a true saccular bifurcation aneurysm while preserving the PCA at the branch origin $(4,78)$. In addition, in some selective cases of dissecting aneurysms, selective stent-assisted coiling with PCA preservation can be performed (Figures 3-5) (38).

\section{Parent Artery Occlusion}

Parent artery occlusion (PAO) is a deconstructive method. For some giant fusiform dissections, serpentine aneurysms, or traumatic pseudoaneurysms when PCA preservation is difficult or impossible, PAO is the last resort (Figure 6) $(79,80)$. PAO can be performed by coiling the proximal PCA, coiling the proximal PCA and aneurysm, or trapping the aneurysm, including the proximal and distal PCA (73).

Sometimes, aneurysm trapping is not necessary, and proximal coiling with/without aneurysm coiling is sufficient. After proximal coiling, blood-flow reversal will alter the hemodynamic stress on the aneurysm, which can produce thrombosis in the aneurysm and reduce the risk of hemorrhage (81). Only loose packing of the aneurysm or the short segment of the PCA is unreliable, resulting in coil compaction and displacement (41).

Due to the rich collateral circulation and hemodynamic balance of the PCA, PAO of the distal P3-P4 segment is safe $(2,82)$. However, PAO of the P1 segment should be avoided because the collateral circulation of the perforators that supply the brainstem and thalamoperforating artery are absent, and PAO will result in a serious infarct $(39,52)$. When PAO is the last resort, preservation of the perorating artery is mandatory, and superselective injection is useful for identifying perforating arteries arising from the proximal PCA (83).

In general, the $\mathrm{P} 2$ segment has well-formed anastomoses, and PAO is safe (38). However, when the PCA is fetal type, due to either an absent or a smaller P1 segment, the P2 segment can send out more perforating arteries (2). In addition, for fetal-type PCA, 

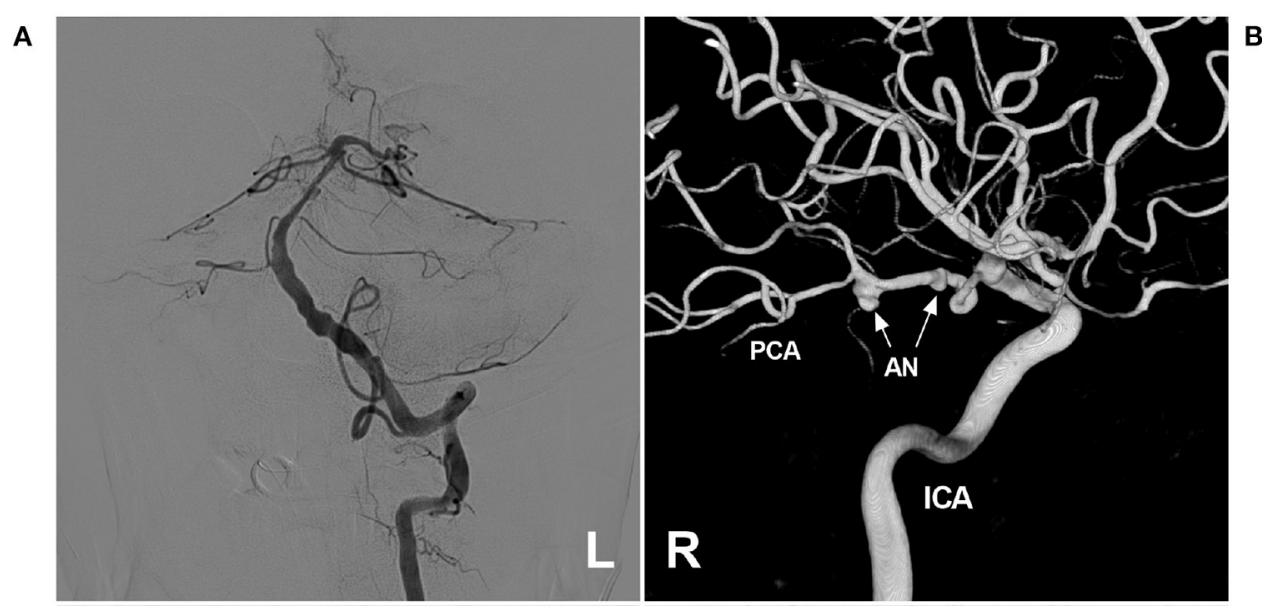

c

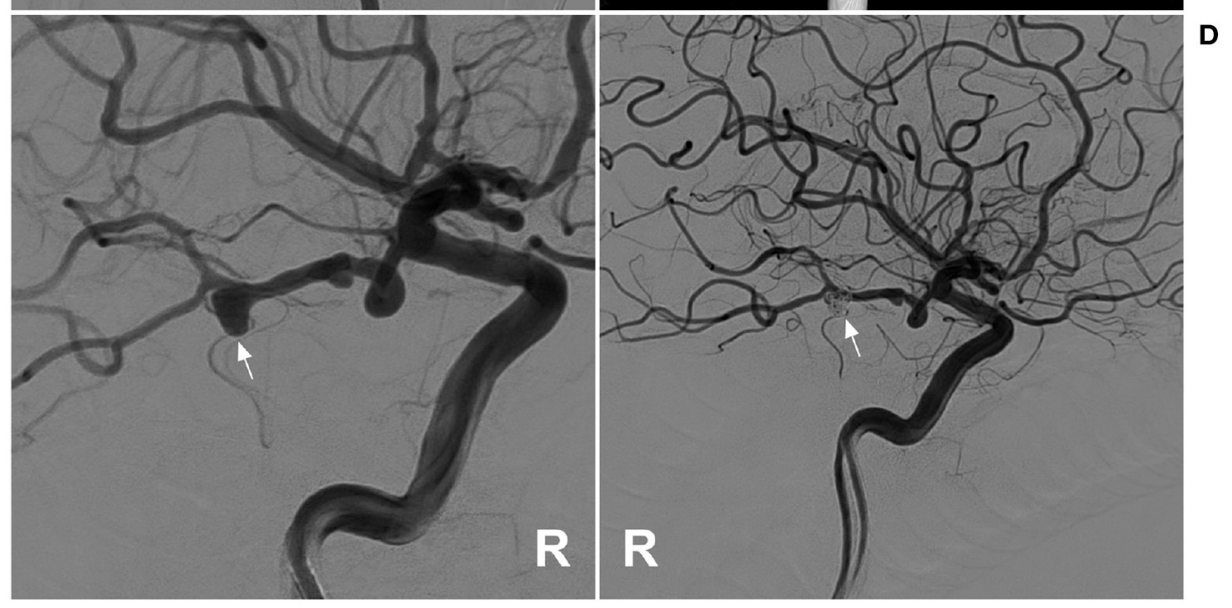

FIGURE 4 | Assisted coiling for P3 segment aneurysm through the ICA. (A) Angiogram of the left VA showing that the BA was slim, and the right PCA was absent. (B) Three-dimensional angiogram of the right ICA showed two aneurysms (arrows) on the fetal-type PCA. (C) Angiogram of the right ICA showed that the large aneurysm (arrow) was planned to perform coiling. (D) Postoperative angiogram of the right ICA showed that the large aneurysm (arrow) was coiled via the ICA system. AN, aneurysm; BA, basilar artery; ICA, internal carotid artery; L, left; PCA, posterior cerebellar artery; R, right; VA, vertebral artery.

leptomeningeal anastomosis between the middle cerebral artery (MCA) and PCA tends to show less development of collaterals (2). Therefore, PAO of the P2 segment should be performed cautiously for fetal-type PCA (5). After PAO, steroids and low molecular weight heparin are recommended to prevent edema and sudden thrombosis of large or giant aneurysms. At the same time, it is important to maintain increased blood pressure for a few days to help the development of functional collaterals (84).

The collateral channels of the PCA region are not easily recognized. Therefore, before $\mathrm{PAO}$, the balloon occlusion test (BOT) is recommended (85). The BOT should be performed when the patient is awake to allow for real-time evaluation of neurological deficits. Additionally, mean arterial pressure can be reduced to $70 \%$ of baseline during the BOT to evaluate the strength of the collateral supply to the territory at risk (22). At the same time, the BOT should be used to assess the retrograde opacification of PCA branches by collaterals (86).

In addition to the BOT, functional tests are recommended, including the superselective Wada test and provocative test
(87-89). The superselective Wada test is performed through a microcatheter in the PCA under local anesthesia. After sodium amyloid injection, the patient undergoes functional examination of the PCA region (87). Under general anesthesia, a superselective provocative test can be performed with methohexital monitoring by electroencephalography or motor/somatosensory evoked potentials $(88,90)$.

In patients who cannot tolerate the BOT or functional tests, strong consideration should be given to EVT allowing for parent artery preservation or to neurosurgical techniques with bypass assistance (22).

\section{EVT for Flow-Related Aneurysms}

In BAVM, DAVF, PAVF, vein of Galen aneurysmal malformations, or ICA occlusion and MMD, flow-related aneurysms of the PCA trunk abide by a similar EVT principle as isolated aneurysms $(49,53)$. However, for PCA trunk aneurysms located on the collateral circulation in MMD and ICA occlusion, especially P1 segment aneurysms, the PCA trunk should be 


\section{A \\ C}
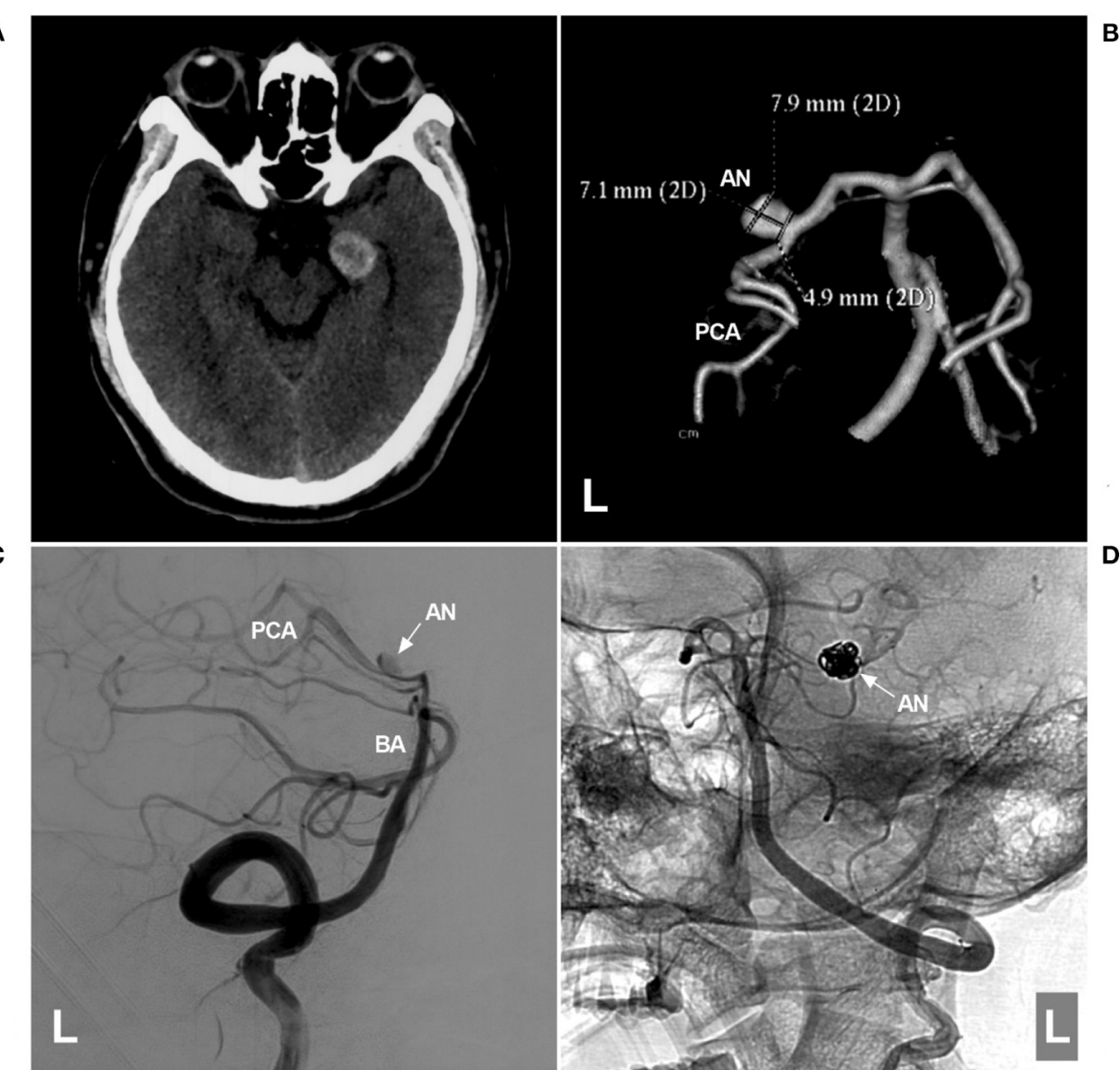

$\mathbf{E}$

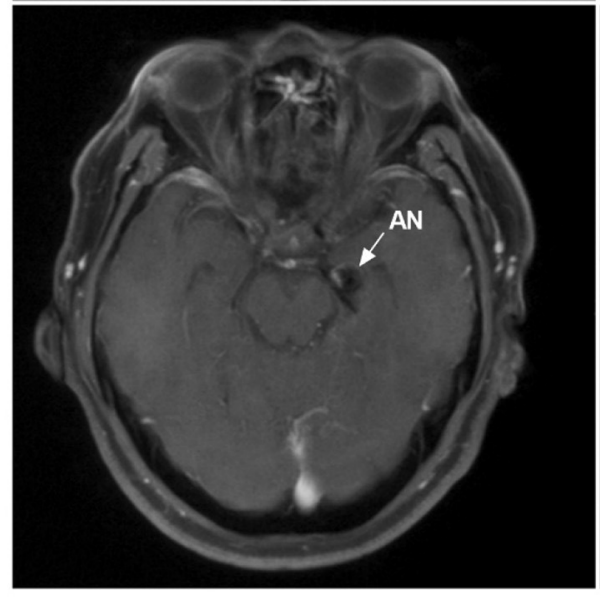

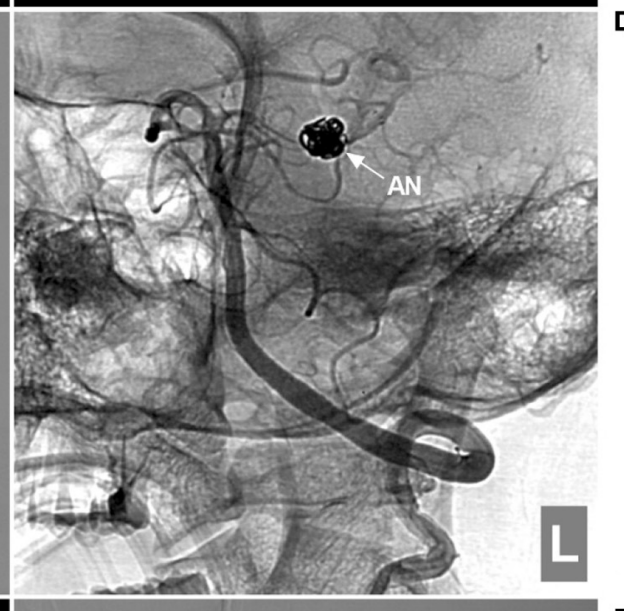

B

D

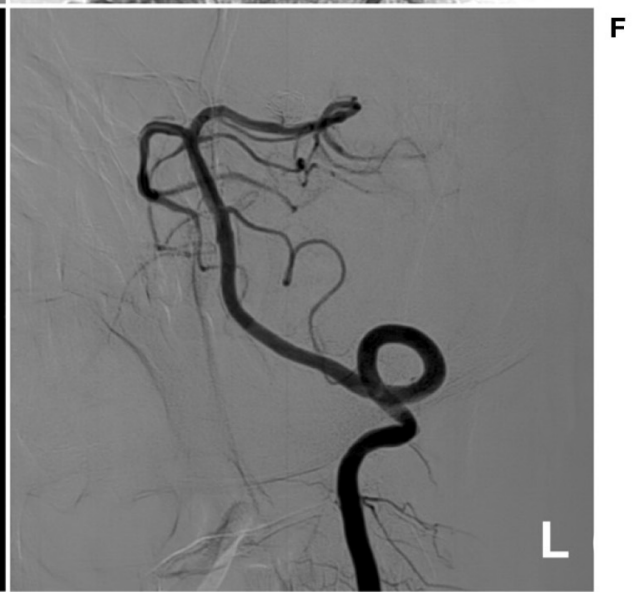

FIGURE 5 | Assisted coiling of P2 segment aneurysm with thrombosis. (A) CT shows a highly dense lesion beside the left midbrain. (B) CTA showing a dissecting aneurysm (AN) on the P2 segment. (C,D) Two-dimensional angiograms of the left VA show the preoperative (C) and postoperative (D) images. In D, the coils (arrow in D) in the aneurysm sac were larger than the aneurysm shape in C, indicating thrombosis in the aneurysm. (E) One-year follow-up MRI showing that the thrombus was absorbed, and the aneurysm (arrow and AN) was smaller than that in A. (F) One-year follow-up angiogram showing no recurrence of the aneurysm. AN, aneurysm; BA, basilar artery; CT, computed tomography; CTA, CT angiography; L, left; MRI, magnetic resonance imaging; PCA, posterior cerebellar artery; VA, vertebral artery.

reconstructed to ensure blood flow to the anterior circulation (Figure 2D) (91, 92). For distal PCA trunk aneurysms in MMD and ICA occlusion, if the collateral circulation is sufficient, PAO can be chosen (11). For flow-related aneurysms of the PCA trunk in BAVM, DAVF, PAVF or vein of Galen aneurysmal malformation cases (Figures 2G,H, 7), aggressive PAO can be considered because the PCA mainly supplies these brain arteriovenous shunts $(16,93)$.

Obliteration of the aneurysm prior to treating these arteriovenous shunts is preferred (12). In BAVMs, the increased 


\section{A \\ C}
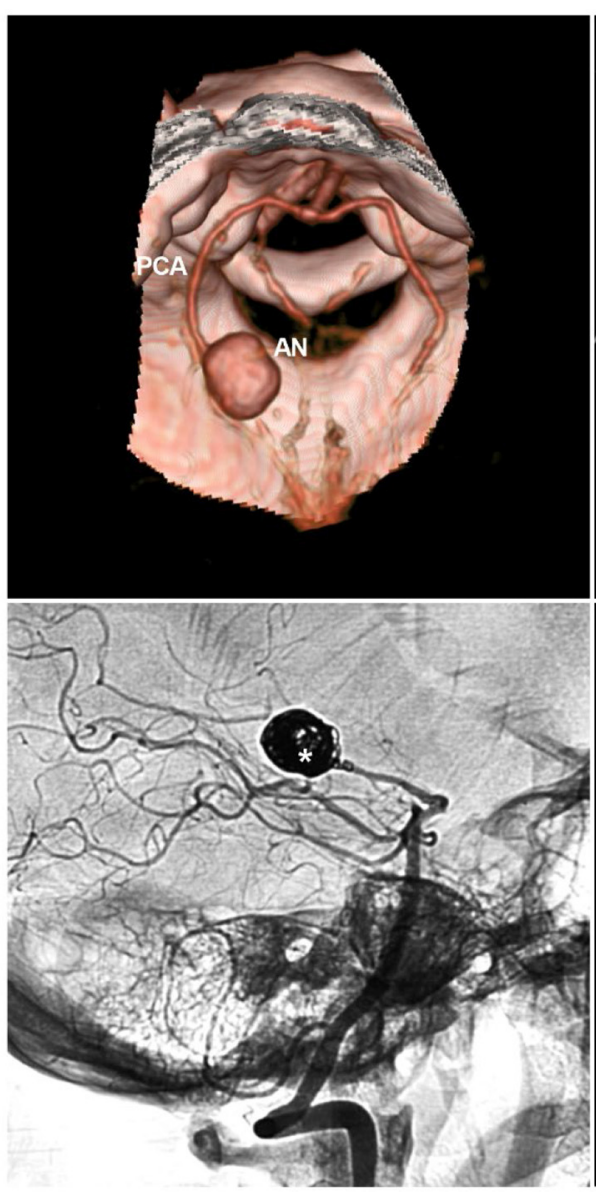

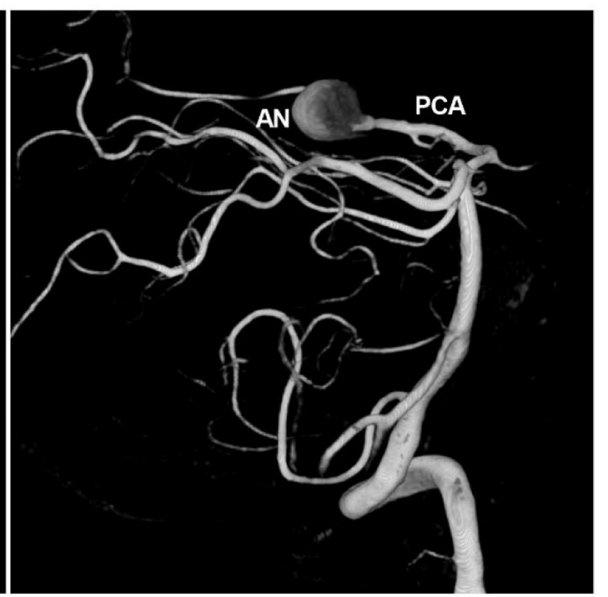

B

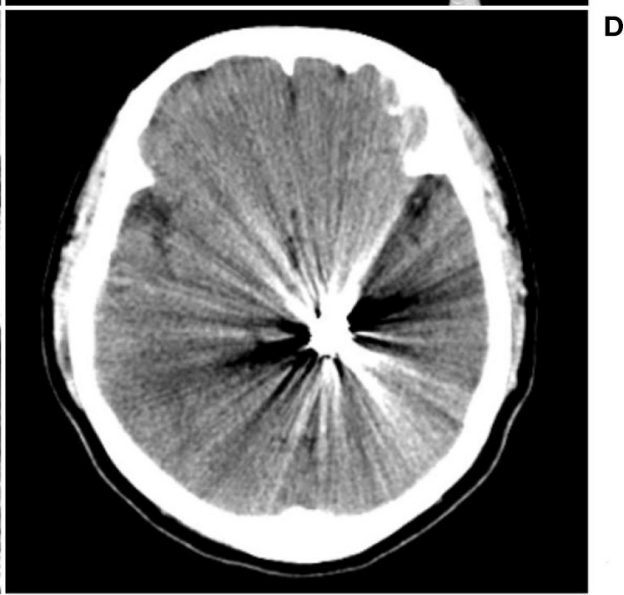

FIGURE 6 | PAO for aneurysm of the P2-P3 junction. (A,B) CTA (A) and three-dimensional angiogram (B) showing the aneurysm (AN) on the left P2-P3 junction. (C) The aneurysm was treated by coiling PAO (asterisk). (D) Postoperative CT showing no infarction in the left occipital lobe. AN, aneurysm; CT, computed tomography; CTA, CT angiography; PAO, parent artery occlusion; PCA, posterior cerebellar artery.

pressure in the feeding artery following EVT can contribute to aneurysm rupture $(94,95)$. In DAVF, the pial arterial supply can be a risk factor for intraoperative hemorrhage during transarterial embolization through dural feeders (55, 96-98). Once the aneurysm is obliterated, BAVM or DAVF can be treated with any method necessary, including embolization via other feeding arteries, surgical removal or radiotherapy (74).

\section{Selection of Embolization Materials}

For EVT with PCA preservation, coiling or stenting is the only choice (Figures 3-5). On rare occasions, a PCA trunk aneurysm can be reconstructed with parent vessel preservation using a combination of a stent and a liquid embolic agent (99). During PAO, when a PCA trunk aneurysm is isolated, coiling is preferred because the distal PCA can be preserved, which is beneficial to collateral circulation establishment (Figure 6).

For PAO of flow-related aneurysms in BAVMs or DAVFs, coiling or liquid embolization materials can be chosen. When liquid embolization material is cast, part of the material floats into the BAVM or DAVF, and the reflex occludes the aneurysm, which is safe. However, caution must be taken to avoid normal vessel occlusion due to a lack of control of the liquid embolization material (Figures 2G,H).

\section{FLOW-DIVERTING STENT}

In the early stages, conventional low metal coverage stents and even coronary stents were used to treat PCA trunk aneurysms (100). However, the effects of these stents are uncertain. Currently, flow-diverting stents (FDSs) are revolutionizing EVT, and off-label FDS use has extended EVT from the proximal ICA aneurysm to distal intracranial artery aneurysms, including those in the PCA trunk, especially unruptured aneurysms with no collateral or poor collateral supply (101).

Current FDS deployment requires a 0.027 -inch microcatheter. For the proximal PCA trunk, the mean diameter is approximately 

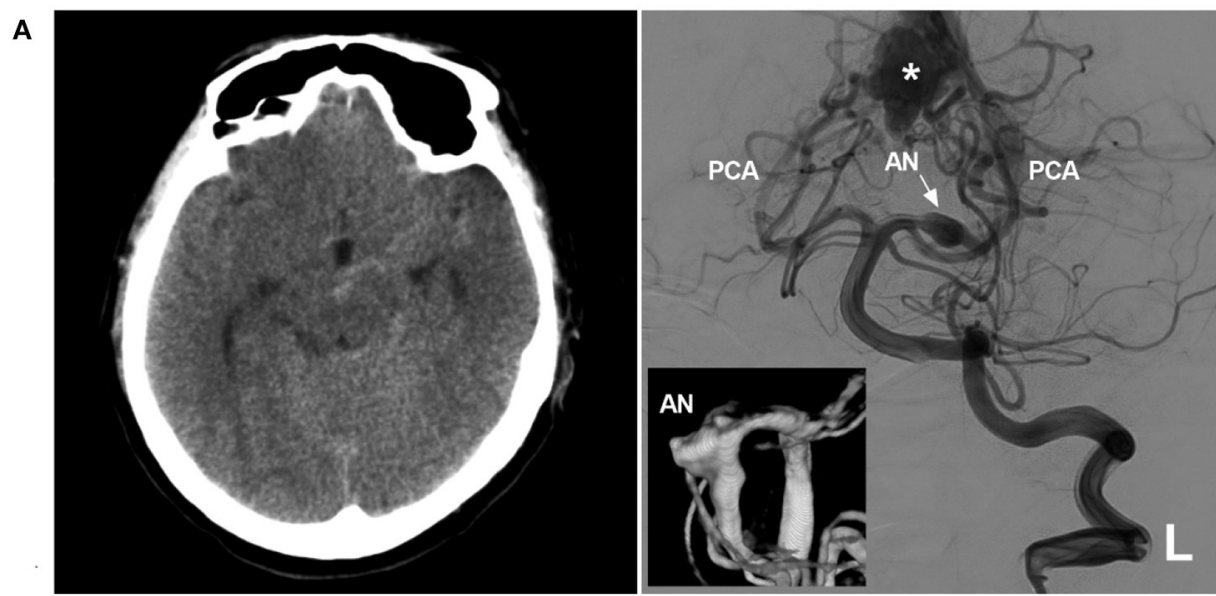

B

C
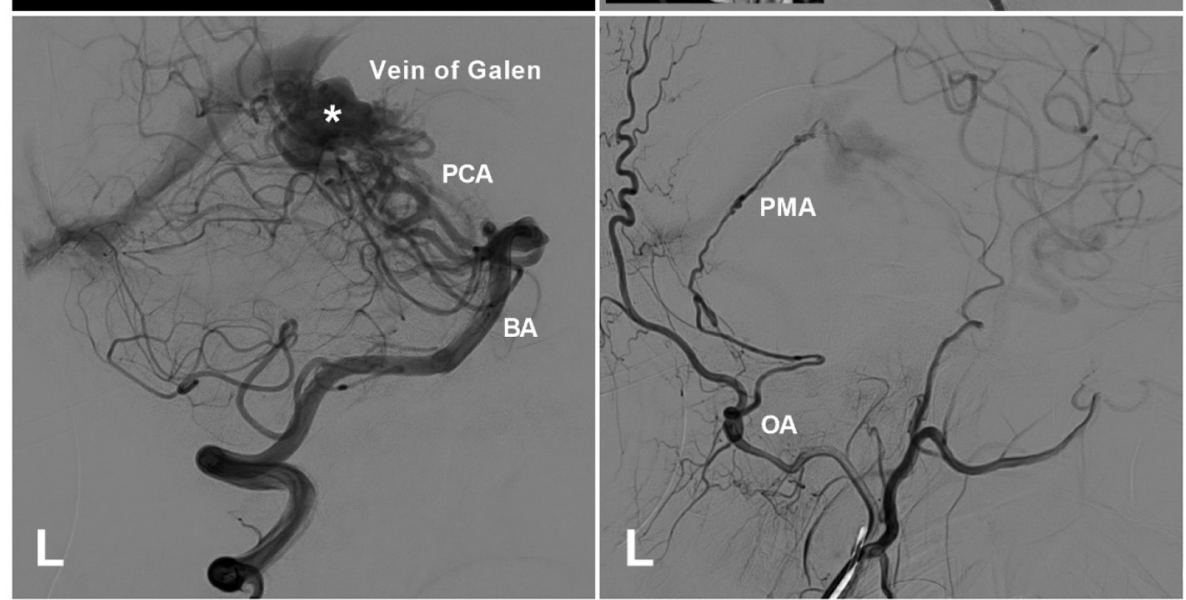

E
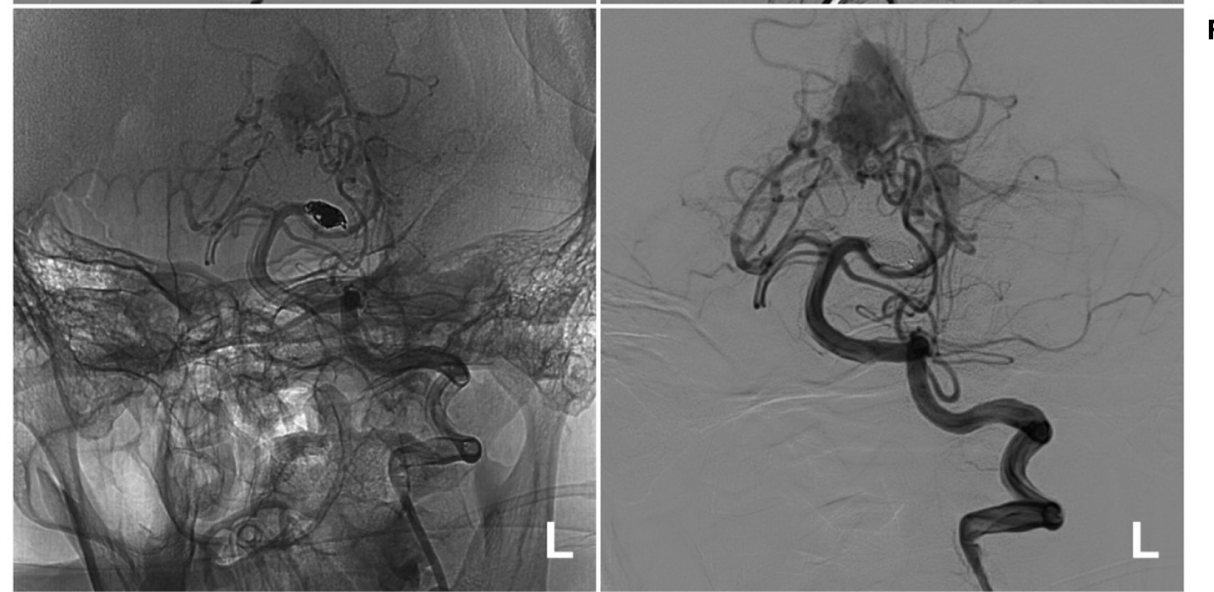

FIGURE 7 | PAO for a proximal PCA aneurysm in the vein of Galen aneurysmal malformation. (A) Computed tomography showing a subarachnoid hemorrhage beside the left midbrain. (B,C) Angiograms of the left VA (B was the anteroposterior view, $C$ was the lateral view) showing a choroidal type of vein of a Galen aneurysmal malformation, and the asterisk indicated a dilated vein of Galen; in B, an aneurysm (arrow and AN) located at the proximal PCA as the feeding artery to the vein of Galen aneurysmal malformation. In the picture inset, the aneurysm was irregular. (D) Angiogram of the left external carotid artery showing that the PMA from the $\mathrm{OA}$ also acts as the feeding artery. $(\mathbf{E}, \mathbf{F})$ Unsubtracted $(\mathbf{E})$ and subtracted $\mathbf{( F )}$ angiograms of the left VA showing that the aneurysm was occluded by coiling PAO. AN, aneurysm; BA, basilar artery; L, left; OA, occipital artery; PAO, parent artery occlusion; PCA, posterior cerebellar artery; PMA, posterior meningeal artery; VA, vertebral artery.

$2 \mathrm{~mm}$, and the length is approximately $5 \mathrm{~cm}$, sufficient for FDS deployment (Figure 8) (21). However, FDS deployment in the distal vessel remains a challenge, although FDS deployment can be successful in a PCA with a tortuous path (102-104). Due to the dense perforator arteries of the P1 segment and the limitation of PCA diameter, perforating artery ischemia 
A

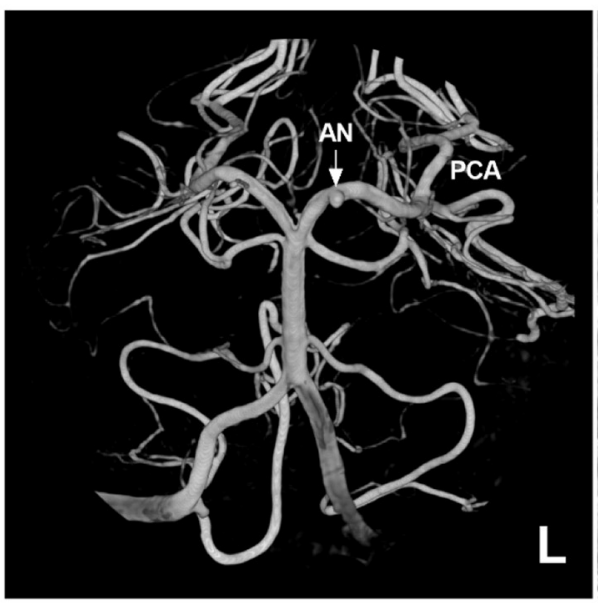

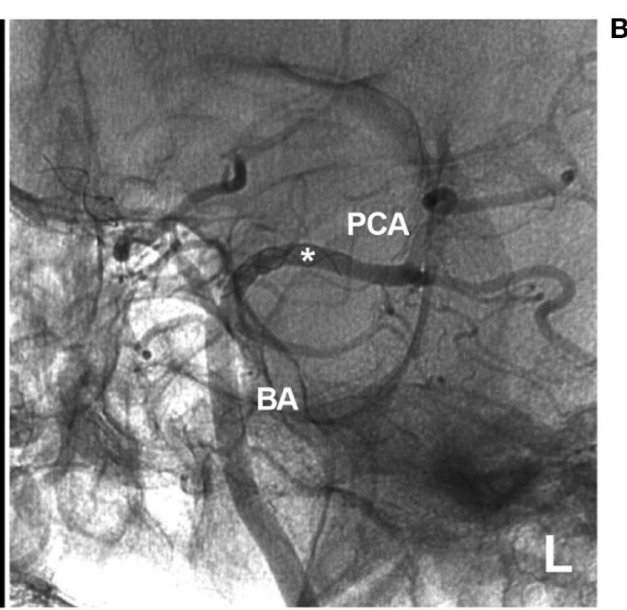

FIGURE 8 | FDS deployment for a proximal PCA aneurysm. (A) Three-dimensional angiogram of the left VA showing a proximal PCA aneurysm (arrow and AN). (B) Unsubtracted angiogram showing FDS deployment (asterisk) covering the aneurysm. AN, aneurysm; BA, basilar artery; FDS, flow-diverting stent; L, left; PCA, posterior cerebellar artery; VA, vertebral artery.

A

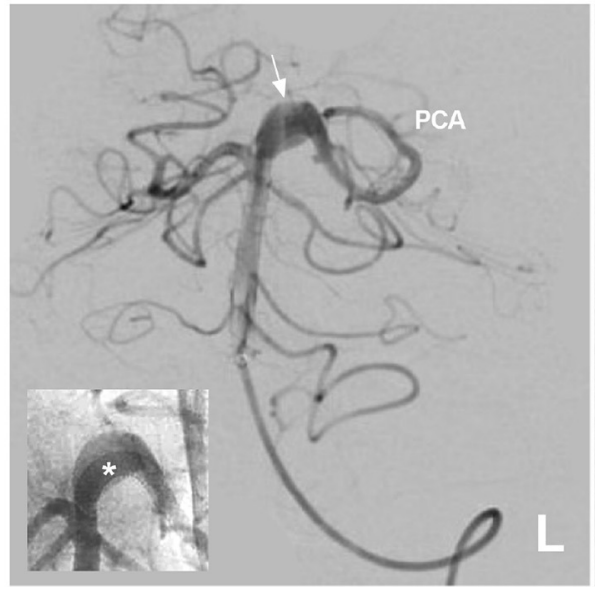

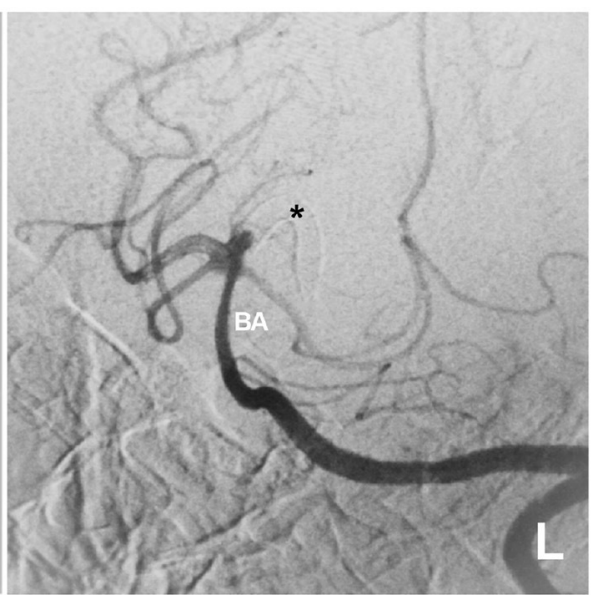

FIGURE 9 | Delayed PCA occlusion after FDS deployment. (A) Angiogram of the left VA showing a proximal fusiform PCA aneurysm (arrow). The inset shows that the FDS (asterisk) was deployed. (B) Six-month follow-up angiogram showing that the proximal PCA was occluded, and the asterisk indicates the FDS location. BA, basilar artery; FDS, flow-diverting stent; L, left; PCA, posterior cerebellar artery; VA, vertebral artery.

and varying degrees of in-stent stenosis or occlusion can occur (Figure 9) (101).

FDS application in ruptured PCA trunk aneurysms remains controversial; at this time, adjunctive coiling might be needed (101, 105, 106).

According to recent reports, FDS deployment has been used to treat flow-related aneurysms in BAVMs $(107,108)$. However, because the feeding arteries are dilated and thin, as in "venolization", and moreover because the feeding artery has a greater burden of hemodynamic stress, flowrelated aneurysms should be treated differently than isolated aneurysms (109). Therefore, more trials are needed to determine whether FDS deployment is feasible for PCA trunk flowrelated aneurysms.

\section{COMPLICATIONS AND PROGNOSIS OF EVT}

Currently, EVT for PCA trunk aneurysms is effective (4). However, complications are inherent, and numerous attempts to navigate microwires and microcatheters can result in infarcts from thromboemboli or injury to arteries (101). Certainly, PAO can result in occipital infarction (Figure 10).

In 2016, Sturiale et al. reviewed 259 PCA trunk aneurysms treated with selective coiling in $37 \%$ of cases, stent-assisted coiling in $2 \%$ of cases, or PAO in $62 \%$ of cases. Immediate complete or near-complete aneurysm occlusion was achieved in $96 \%$ of cases, with an overall complication rate of 15\% (105). In 2018, Wallace et al. performed a systematic review of 50 

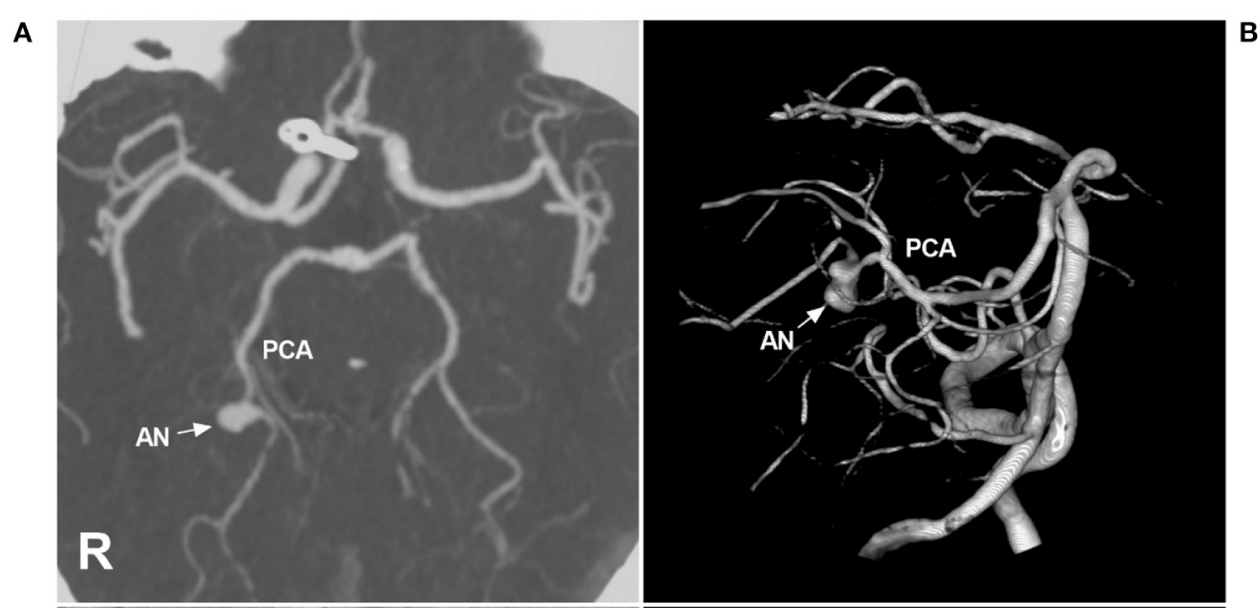

C
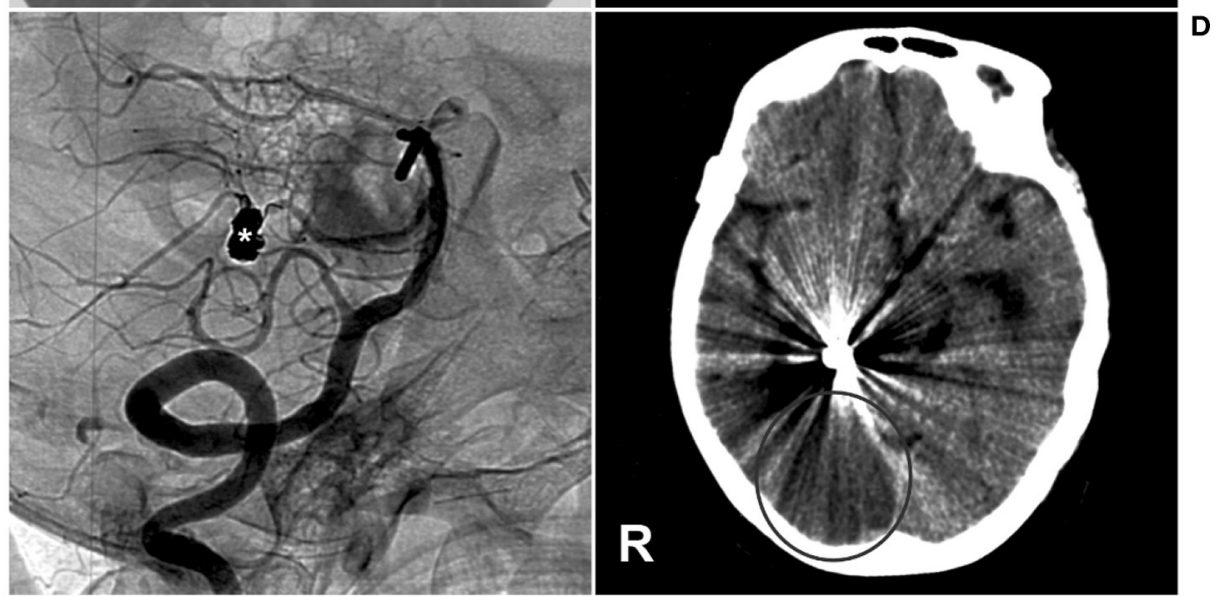

FIGURE 10 | Brain infarction after PAO for P3 segment aneurysms. (A,B) CTA (A) and three-dimensional angiogram (B) showing the aneurysm (arrow and AN) on the right P3 segment. (C) The aneurysm (asterisk) was treated by coiling PAO. (D) Postoperative CT showing infarction in the right occipital lobe. AN, aneurysm; CT, computed tomography; CTA, CT angiography; PCA, posterior cerebellar artery; R, right; VA, vertebral artery.

PCA trunk aneurysms treated by FDS deployment and found a complete aneurysm occlusion rate of $88 \%$ and a complication rate of $26 \%$, and no recurrence was found (110).

Therefore, conventional EVT (especially PAO) and FDS deployment of PCA trunk aneurysms are good choices and are effective.

\section{SUMMARY}

The PCA is a very important artery, and aneurysms can occur along the PCA trunk. They can occur alone or as flowrelated aneurysms in association with high-flow arteriovenous shunt diseases or moyamoya disease and ICA occlusion. Some aneurysms of the PCA trunk require treatment, especially

\section{REFERENCES}

1. Ulm AJ, Tanriover N, Kawashima M, Campero A, Bova FJ, Rhoton A. Microsurgical approaches to the perimesencephalic ruptured or large/giant aneurysms, and EVT is a good choice. For proximal aneurysms, the PCA should be preserved; for distal aneurysms, PAO can be performed. Recently, the FDS has revolutionized the treatment of unruptured dissecting aneurysms in the PCA trunk. Despite the associated complications, EVT remains an effective method for treating PCA trunk aneurysms and can result in a good prognosis.

\section{AUTHOR CONTRIBUTIONS}

JY contributed to the conception, design of the manuscript, and critically revised the manuscript. $\mathrm{KH}$ and $\mathrm{XL}$ wrote the manuscript and collected the medical records of the patients. All authors approved the final version of this manuscript. cisterns and related segments of the posterior cerebral artery: comparison using a novel application of image guidance. Neurosurgery. (2004) 54:1313-27. doi: 10.1227/01.NEU.0000126129.687 07.E7 
2. Matsumura H, Kato N, Fujiwara Y, Hosoo H, Yamazaki T, Yasuda S, et al. Endovascular treatments for posterior cerebral artery aneurysms and vascular insufficiency of fetal-type circulation after parent artery occlusion. $J$ Clin Neurosci. (2016) 32:41-6. doi: 10.1016/j.jocn.2015.12.049

3. de Sousa AA, Dantas FL, Neto AP, Carvalho GT. Giant posterior cerebral artery aneurysm in a 4-year-old child: case report. Surg Neurol. (1996) 45:31-5. doi: 10.1016/0090-3019(95)00362-2

4. Ciceri EF, Klucznik RP, Grossman RG, Rose JE, Mawad ME. Aneurysms of the posterior cerebral artery: classification and endovascular treatment. AJNR Am J Neuroradiol. (2001) 22:27-34.

5. Xu J, Xu L, Wu Z, Chen X, Yu J, Zhang J. Fetal-type posterior cerebral artery: the pitfall of parent artery occlusion for ruptured $\mathrm{P}(2)$ segment and distal aneurysms. J Neurosurg. (2015) 123:906-14. doi: 10.3171/2014.9.JNS1442

6. Ferrante L, Acqui M, Trillo G, Lunardi P, Fortuna A. Aneurysms of the posterior cerebral artery: do they present specific characteristics? Acta Neurochir (Wien). (1996) 138:840-52. doi: 10.1007/BF01411263

7. Statham P, Johnston R, Coutinho C, Hadley D. Double giant fusiform aneurysms of the posterior cerebral artery. Surg Neurol. (1990) 33:4851. doi: 10.1016/0090-3019(90)90225-E

8. Kobkitsuksakul C, Somboonnitiphol K, Apirakkan M, Lueangapapong P, Chanthanaphak E. Dolichoectasia of the internal carotid artery terminus, posterior communicating artery, and posterior cerebral artery: the embryonic caudal ramus internal carotid segmental vulnerability legacy. Interv Neuroradiol. (2020) 26:124-30. doi: 10.1177/1591019919871394

9. Zhang J, Shi X, Liu F, Sun Y, Qian H, Zhou Z. Serpentine aneurysm of the posterior cerebral artery treated by internal maxillary artery bypass followed by parent artery occlusion: a case report and literature review. Acta Neurochir (Wien). (2019) 161:1183-9. doi: 10.1007/s00701-019-03902-8

10. Goehre F, Kamiyama H, Noda K, Ota N, Tsuboi T, Miyata S, et al. Technical description of the medial and lateral anterior temporal approach for the treatment of complex proximal posterior cerebral artery aneurysms. World Neurosurg. (2016) 86:490-6. doi: 10.1016/j.wneu.2015.09.068

11. Hou K, Li G, Luan $\mathrm{T}, \mathrm{Xu} \mathrm{K}, \mathrm{Yu}$ J. The prospects and pitfalls in the endovascular treatment of moyamoya diseaseassociated intracranial aneurysms. Neurosurg Rev. (2021) 44:261-71. doi: 10.1007/s10143-020-01261-y

12. Hou K, Li C, Su H, Yu J. Imaging characteristics and endovascular treatment of brain arteriovenous malformations mainly fed by the posterior cerebral artery. Front Neurol. (2020) 11:609461. doi: 10.3389/fneur.2020.609461

13. Su $\mathrm{H}, \mathrm{Xu} \mathrm{K}$, Wang $\mathrm{Y}, \mathrm{Yu}$ J. Is the middle meningeal artery the optimal path for dural arteriovenous fistula embolization? Front Neurol. (2021) 12:675355. doi: 10.3389/fneur.2021.675355

14. Gross BA, Ropper AE, Du R. Cerebral dural arteriovenous fistulas and aneurysms. Neurosurg Focus. (2012) 32:E2. doi: 10.3171/2011.12.FOCUS11336

15. Griffin AS, Befera N, Hauck E. Onyx embolization of a pial AV fistula with a giant venous varix using a flow-directed Scepter balloon catheter: technical note. Interv Neuroradiol. (2018) 24:702-5. doi: 10.1177/1591019918781670

16. Pearl M, Gomez J, Gregg L, Gailloud P. Endovascular management of vein of Galen aneurysmal malformations. Influence of the normal venous drainage on the choice of a treatment strategy. Childs Nerv Syst. (2010) 26:1367-79. doi: 10.1007/s00381-010-1257-0

17. Moron F, Benndorf G, Akpek S, Dempsy R, Strother CM. Spontaneous thrombosis of a traumatic posterior cerebral artery aneurysm in a child. AJNR Am J Neuroradiol. (2005) 26:58-60.

18. Ros de. San Pedro J, Cuartero Perez B. Completely thrombosed aneurysms of the posterior cerebral artery: a comprehensive review. J Neurol Surg A Cent Eur Neurosurg. (2017) 78:488-501. doi: 10.1055/s-0037-1602700

19. Terasaka S, Sawamura Y, Kamiyama H, Fukushima T. Surgical approaches for the treatment of aneurysms on the P2 segment of the posterior cerebral artery. Neurosurgery. (2000) 47:35964. doi: 10.1097/00006123-200008000-00016

20. Takeshita T, Nagamine T, Ishihara K, Kaku Y. Stent-assisted coil embolization of a recurrent posterior cerebral artery aneurysm following surgical clipping. Neuroradiol J. (2017) 30:99-103. doi: 10.1177/1971400916678243

21. Yu J, Lv X. Flow diversion for intracranial aneurysms beyond the circle of willis. Front Neurol. (2021) 12:674966. doi: 10.3389/fneur.2021.674966
22. Kim YB, Lee JW, Huh SK, Kim BM, Kim DJ. Outcomes of multidisciplinary treatment for posterior cerebral artery aneurysms. Clin Neurol Neurosurg. (2013) 115:2062-8. doi: 10.1016/j.clineuro.2013.07.004

23. Bulsara KR, Zomorodi A, Provenzale JM. Anatomic variant of the posterior cerebral artery. AJR Am J Roentgenol. (2007) 188:W395. doi: 10.2214/AJR.06.0991

24. Veras TW, Elhert GW. Variation of the posterior cerebral artery and its embryological explanation: a cadaveric study. Bol Asoc Med $P R$. (2010) 102:55-8.

25. Gunnal SA, Farooqui MS, Wabale RN. Study of posterior cerebral artery in human cadaveric brain. Anat Res Int. (2015) 2015:681903. doi: 10.1155/2015/681903

26. Cilliers K, Page BJ. Variation and anomalies of the posterior cerebral artery: review and pilot study. Turk Neurosurg. (2019) 29:1-8. doi: 10.5137/1019-5149.JTN.21443-17.2

27. Uchino A, Saito N, Takahashi M, Okano N, Tanisaka M. Variations of the posterior cerebral artery diagnosed by MR angiography at 3 tesla. Neuroradiology. (2016) 58:141-6. doi: 10.1007/s00234-015-1614-5

28. Hacein-Bey L, Muszynski CA, Varelas PN. Saccular aneurysm associated with posterior cerebral artery fenestration manifesting as a subarachnoid hemorrhage in a child. AJNR Am J Neuroradiol. (2002) 23:1291-4.

29. Rhoton AL. The supratentorial arteries. Neurosurgery. (2002) 51:S53120. doi: 10.1097/00006123-200210001-00003

30. Zeal AA, Rhoton AL. Microsurgical anatomy of the posterior cerebral artery. J Neurosurg. (1978) 48:534-59. doi: 10.3171/jns.1978.48.4.0534

31. Uz A. The segmentation of the posterior cerebral artery: a microsurgical anatomic study. Neurosurg Rev. (2019) 42:15561. doi: 10.1007/s10143-018-0972-y

32. Yamahata H, Tokimura H, Hirabaru M, Hirano H, Arita K. Aneurysm on the cortical branch ( $\mathrm{P} 4$ segment) of the posterior cerebral artery. Case report Neurol Med Chir (Tokyo). (2010) 50:1084-7. doi: 10.2176/nmc.50.1084

33. Parraga RG, Ribas GC, Andrade SE, de Oliveira E. Microsurgical anatomy of the posterior cerebral artery in three-dimensional images. World Neurosurg. (2011) 75:233-57. doi: 10.1016/j.wneu.2010.10.053

34. Caruso G, Vincentelli F, Giudicelli G, Grisoli F, Xu T, Gouaze A. Perforating branches of the basilar bifurcation. J Neurosurg. (1990) 73:25965. doi: 10.3171/jns.1990.73.2.0259

35. Kaya AH, Dagcinar A, Ulu MO, Topal A, Bayri Y, Ulus A, et al. The perforating branches of the P1 segment of the posterior cerebral artery. J Clin Neurosci. (2010) 17:80-4. doi: 10.1016/j.jocn.2009.03.046

36. Binning MJ, Couldwell WT. Fenestration of the oculomotor nerve by a duplicated posterior cerebral artery and aneurysm. Case report J Neurosurg. (2009) 111:84-6. doi: 10.3171/2009.2.JNS081688

37. Iwashita T, Tanaka Y, Hongo K, Koyama Ji J, Koyama T, Nitta J. Aneurysm originating from the fenestration of the posterior cerebral artery: case report. Neurosurgery. (2002) 50:881-4. doi: 10.1097/00006123-200204000-00040

38. Park W, Kwon DH, Ahn JS, Lee SH, Park JC, Kwun BD. Treatment strategies for dissecting aneurysms of the posterior cerebral artery. Acta Neurochir (Wien). (2015) 157:1633-43. doi: 10.1007/s00701-015-2526-1

39. Roh HG, Kim SS, Han H, Kang HS, Moon WJ, Byun HS. Endovascular treatment of posterior cerebral artery aneurysms using detachable coils. Neuroradiology. (2008) 50:237-42. doi: 10.1007/s00234-007-0321-2

40. Lazinski D, Willinsky RA, TerBrugge K, Montanera W. Dissecting aneurysms of the posterior cerebral artery: angioarchitecture and a review of the literature. Neuroradiology. (2000) 42:12833. doi: $10.1007 / \mathrm{s} 002340050031$

41. Horie N, Kawahara I, Kitagawa N, Morikawa M, Tsutsumi K, Kaminogo M, et al. Recanalization after endovascular occlusion of a dissecting aneurysm of the posterior cerebral artery-A case report and review of the literature. Clin Neurol Neurosurg. (2008) 110:411-5. doi: 10.1016/j.clineuro.2007.12.022

42. Saito H, Ogasawara K, Kubo Y, Tomitsuka N, Ogawa A. Treatment of ruptured fusiform aneurysm in the posterior cerebral artery with posterior cerebral artery-superior cerebellar artery anastomosis combined with parent artery occlusion: case report. Surg Neurol. (2006) 65:6214. doi: 10.1016/j.surneu.2005.09.009

43. $\mathrm{Xu} \mathrm{K}, \mathrm{Yu} \mathrm{T}$, Guo $\mathrm{Y}$, Yu J. Study and therapeutic progress on intracranial serpentine aneurysms. Int J Med Sci. (2016) 13:432-9. doi: 10.7150/ijms.14934 
44. Hsu YW, Kao HW, Lin GY, Lai CH, Lee JT. Giant serpentine aneurysm of the posterior cerebral artery: a rare clinical entity and technical challenge in diagnosis and treatment. Neurol India. (2017) 65:9178. doi: 10.4103/neuroindia.NI_123_17

45. Crum BA, Wijdicks EF. Thalamic hematoma from a ruptured posterior cerebral artery aneurysm. Cerebrovasc Dis. (2000) 10:475-7. doi: 10.1159/000016111

46. Orita T, Tsurutani T, Izumihara A, Kajiwara K. Distal posterior cerebral artery aneurysms-three case reports. Neurol Med Chir (Tokyo). (1994) 34:692-6. doi: 10.2176/nmc.34.692

47. Huang Y, Zhou P, Wang Z, Han Q. Disappearance of ruptured posterior cerebral artery aneurysm associated with internal carotid artery occlusion after superficial temporal artery-to-middle cerebral artery bypass. World Neurosurg. (2018) 116:178-81. doi: 10.1016/j.wneu.2018.05.096

48. Ko A, Filardi T, Giussani C, Ghodke R, Browd SR. An intracranial aneurysm and dural arteriovenous fistula in a newborn. Pediatr Neurosurg. (2010) 46:450-6. doi: 10.1159/000323420

49. Shibuya T, Hayashi N, A. case of posterior cerebral artery aneurysm associated with idiopathic bilateral internal carotid artery occlusion: case report. Surg Neurol. (1999) 52:617-22. doi: 10.1016/S0090-3019(99)00134-2

50. Ide M, Jimbo M, Yamamoto M, Hagiwara S. Posterior cerebral artery aneurysm associated with unilateral internal carotid artery agenesis-Case report. Neurol Med Chir (Tokyo). (1995) 35:825-9. doi: 10.2176/nmc.35.825

51. Iwama T, Todaka T, Hashimoto N. Direct surgery for major artery aneurysm associated with moyamoya disease. Clin Neurol Neurosurg. (1997) 99:S1913. doi: 10.1016/S0303-8467(97)00081-4

52. Nishio A, Hara M, Otsuka Y, Tsuruno T, Murata T. Endovascular treatment of posterior cerebral aneurysm associated with Moyamoya disease. J Neuroradiol. (2004) 31:60-2. doi: 10.1016/S0150-9861(04)96879-4

53. Yousaf I, Gray WJ, McKinstry CS, Choudhari KA. Development of posterior circulation aneurysm in association with bilateral internal carotid artery occlusion. $\mathrm{Br} J$ Neurosurg. (2003) 17:471-2. doi: 10.1080/02688690310001613871

54. Wolf RL, Imbesi SG, Galetta SL, Hurst RW, Sinson GP, Grossman RI. Development of a posterior cerebral artery aneurysm subsequent to occlusion of the contralateral internal carotid artery for giant cavernous aneurysm. Neuroradiology. (2002) 44:443-6. doi: 10.1007/s00234-001-0723-5

55. Osada T, Krings T. Intracranial dural arteriovenous fistulas with pial arterial supply. Neurosurgery. (2019) 84:104-15. doi: 10.1093/neuros/nyy014

56. Selvamurugan V, Prasad SN, Singh V, Neyaz Z. Traumatic dissecting pathology of posterior cerebral artery: a report of two casesaneurysm and pial arteriovenous fistula. BMJ Case Rep. (2021) 14:e237722. doi: 10.1136/bcr-2020-237722

57. Cagnazzo F, Peluso A, Vannozzi R, Brinjikji W, Lanzino G, Perrini P. Arterial aneurysms associated with intracranial dural arteriovenous fistulas: epidemiology, natural history, and management. A systematic review. Neurosurg Rev. (2019) 42:277-85. doi: 10.1007/s10143-017-0929-6

58. Rumboldt Z, Beros V, Klanfar Z. Multiple cerebral aneurysms and a dural arteriovenous fistula in a patient with polyarteritis nodosa. Case illustration J Neurosurg. (2003) 98:434. doi: 10.3171/jns.2003.98.2.0434

59. Cagnazzo F, Brinjikji W, Lanzino G. Arterial aneurysms associated with arteriovenous malformations of the brain: classification, incidence, risk of hemorrhage, and treatment-a systematic review. Acta Neurochir (Wien). (2016) 158:2095-104. doi: 10.1007/s00701-016-2957-3

60. Morgan MK, Alsahli K, Wiedmann M, Assaad NN, Heller GZ. Factors associated with proximal intracranial aneurysms to brain arteriovenous malformations: a prospective cohort study. Neurosurgery. (2016) 78:78792. doi: 10.1227/NEU.0000000000001114

61. Eliava S, Dmitriev A, Shekhtman O, Yakovlev S, Kheireddin A, Pilipenko Y. Treatment of brain arteriovenous malformations with hemodynamic aneurysms: a series of 131 consecutive cases. World Neurosurg. (2018) 110:e917-e27. doi: 10.1016/j.wneu.2017.11.114

62. Honda M, Tsutsumi K, Yokoyama H, Yonekura M, Nagata I. Aneurysms of the posterior cerebral artery: retrospective review of surgical treatment. Neurol Med Chir (Tokyo). (2004) 44:164-8. doi: 10.2176/nmc.44.164

63. Martinez-Perez R, Pelz DM, Lownie SP. De novo giant posterior cerebral artery aneurysm developing 25 years after basilar bifurcation aneurysm treatment using a Drake tourniquet: case report and implications for aneurysm follow-up. J Neurosurg. (2018) 128:1028-31. doi: 10.3171/2016.11.JNS161740

64. Nistri M, Perrini P, Di Lorenzo N, Cellerini M, Villari N, Mascalchi M. Thirdnerve palsy heralding dissecting aneurysm of posterior cerebral artery: digital subtraction angiography and magnetic resonance appearance. J Neurol Neurosurg Psychiatry. (2007) 78:197-8. doi: 10.1136/jnnp.2006.098129

65. Yoshioka H, Hotta T, Taniguchi E, Hashimoto N, Kinoshita Y, Ohba S, et al. De novo distal posterior cerebral artery aneurysm. Surg Neurol. (2003) 60:534-9. doi: 10.1016/S0090-3019(03)00205-2

66. Vilela P, Goulao A. Paediatric dissecting posterior cerebral aneurysms: report of two cases and review of the literature. Neuroradiology. (2006) 48:5418. doi: 10.1007/s00234-006-0086-Z

67. Tanaka S, Sagiuchi T, Kobayashi I. Ruptured pediatric posterior cerebral artery aneurysm 9 years after the onset of Kawasaki disease: a case report. Childs Nerv Syst. (2007) 23:701-6. doi: 10.1007/s00381-006-0263-8

68. Meena AK, Sitajayalakshmi S, Prasad VS, Murthy JM. Mycotic aneurysm on posterior cerebral artery: resolution with medical therapy. Neurol India. (2000) 48:276-8.

69. Singla N, Umredkar A, Mohindra S, Pathak A. Ruptured posterior cerebral artery aneurysm in association with neurofibromatosis type 2-a case report. Br J Neurosurg. (2011) 25:322-3. doi: 10.3109/02688697.2010.546897

70. Fukaya R, Yanagisawa K, Fukuchi M, Fujii K. Posterior cerebral artery giant aneurysm associated with bilateral internal carotid artery occlusion in a Klippel-Trenaunay syndrome patient: a case report. Br J Neurosurg. (2019) 33:591-3. doi: 10.1080/02688697.2017.1394446

71. Rezai AR, Lee M, Kite C, Smyth D, Jafar JJ. Traumatic posterior cerebral artery aneurysm secondary to an intracranial nail: case report. Surg Neurol. (1994) 42:312-5. doi: 10.1016/0090-3019(94)90399-9

72. Zhang $\mathrm{C}$, Chen $\mathrm{H}$, Bai R. Traumatic aneurysm on the posterior cerebral artery following blunt trauma in a 14-year-old girl: case report. Neuropediatrics. (2011) 42:204-6. doi: 10.1055/s-0031-1291221

73. Sasaki O, Koizumi T, Ito Y, Sorimachi T, Koike T, Tanaka R. Dissecting aneurysm of the posterior cerebral artery treated with proximal ligation. Surg Neurol. (1992) 37:394-401. doi: 10.1016/0090-3019(92)90011-B

74. Hamada J, Morioka M, Yano S, Todaka T, Kai Y, Kuratsu J. Clinical features of aneurysms of the posterior cerebral artery: a 15-year experience with 21 cases. Neurosurgery. (2005) 56:662-70. doi: 10.1227/01.NEU.0000156199.53041.32

75. Horiuchi R, Yoshioka H, Kanemaru K, Hashimoto K, Yagi T, Murayama H, et al. Iodine-123-Iomazenil SPECT revealed recovery of neuronal viability in association with improvement in symptoms following treatment for obstructive hydrocephalus due to a giant posterior cerebral artery aneurysm. World Neurosurg. (2020) 137:341-4. doi: 10.1016/j.wneu.2020.02.067

76. Drake CG. Giant intracranial aneurysms: experience with surgical treatment in 174 patients. Clin Neurosurg. (1979) 26:12-95. doi: 10.1093/neurosurgery/26.CN_suppl_1.12

77. Yamaguchi S, Ito O, Maeda Y, Murata H, Imamoto N, Yuhi F, et al. Coil embolization for a ruptured posterior cerebral artery aneurysm with vertebrobasilar dolichoectasia. Neurol Med Chir (Tokyo). (2011) 51:65760. doi: $10.2176 /$ nmc.51.657

78. Schlamann M, Doerfler A, Schoch B, Forsting M, Wanke I. Balloon-assisted coil embolization of a posterior cerebral artery aneurysm via a persistent primitive trigeminal artery: technical note. Neuroradiology. (2006) 48:9314. doi: 10.1007/s00234-006-0149-1

79. Belec L, Cesaro P, Brugieres P, Gray F. Tumor-simulating giant serpentine aneurysm of the posterior cerebral artery. Surg Neurol. (1988) 29:2105. doi: 10.1016/0090-3019(88)90008-0

80. Sawlani V, Handique A, Phadke RV. Case report: endovascular parent artery occlusion in a fusiform aneurysm of posterior cerebral artery. Clin Radiol. (2004) 59:954-60. doi: 10.1016/j.crad.2004.03.024

81. Wang H, Du R, Stary J, Gkogkas C, Kim D, Day A, et al. Dissecting aneurysms of the posterior cerebral artery: current endovascular/surgical evaluation and treatment strategies. Neurosurgery. (2012) 70:1581-8. doi: 10.1227/NEU.0b013e31824c00f4

82. Lazzaro MA, Ouyang B, Chen M. The role of circle of Willis anomalies in cerebral aneurysm rupture. J Neurointerv Surg. (2012) 4:22-6. doi: 10.1136/jnis.2010.004358 
83. Oishi H, Tanoue S, Teranishi K, Hasegawa H, Nonaka S, Magami S, et al. Endovascular parent artery occlusion of proximal posterior cerebral artery aneurysms: a report of two cases. J Neurointerv Surg. (2016) 8:5913. doi: 10.1136/neurintsurg-2015-011762

84. Arat A, Islak C, Saatci I, Kocer N, Cekirge S. Endovascular parent artery occlusion in large-giant or fusiform distal posterior cerebral artery aneurysms. Neuroradiology. (2002) 44:700-5. doi: 10.1007/s00234-002-0747-5

85. Yamashita K, Taki W, Nishi S, Sadato A, Kikuchi H, Iwata H, et al. Treatment of unclippable giant posterior cerebral artery aneurysms with detachable balloons-report of three cases. Neurol Med Chir (Tokyo). (1992) 32:67983. doi: $10.2176 / \mathrm{nmc} .32 .679$

86. Jayakumar PN, Desai S, Srikanth SG, Ravishankar S, Kovoor JM. Relevance of occlusion test in endovascular coiling of posterior cerebral artery (p2 segment) aneurysms. Interv Neuroradiol. (2004) 10:23548. doi: 10.1177/159101990401000306

87. Rajpal S, Moftakhar R, Bauer AM, Turk AS, Niemann DB. Superselective Wada test for ruptured spontaneous fusiform middle cerebral artery aneurysm: a technical case report. J Neurointerv Surg. (2011) 3:23741. doi: 10.1136/jnis.2010.002220

88. Bican O, Cho C, Lee L, Nguyen V, Le S, Heit J, et al. Positive pharmacologic provocative testing with methohexital during cerebral arteriovenous malformation embolization. Clin Imaging. (2018) 51:1559. doi: 10.1016/j.clinimag.2018.02.014

89. Schmalz PGR, Alturki A, Ogilvy CS, Thomas AJ. Ruptured distal anterior choroidal artery aneurysm treated with superselective provocative testing and coil embolization. World Neurosurg. (2017) 105:1032e19e22. doi: 10.1016/j.wneu.2017.05.176

90. Isozaki M, Satow T, Matsushige T, Mori H, Iihara K. Superselective provocative test with propofol using motor-evoked potential monitoring for managing cerebral arteriovenous malformations fed by the anterior choroidal artery. J Stroke Cerebrovasc Dis. (2016) 25:e153-7. doi: 10.1016/j.jstrokecerebrovasdis.2016.05.034

91. Kim JH, Kwon TH, Kim JH, Chong K, Yoon W. Intracranial aneurysms in adult moyamoya disease. World Neurosurg. (2018) 109:e175-e82. doi: 10.1016/j.wneu.2017.09.127

92. Luo Q, Wang $\mathrm{H}, \mathrm{Xu} \mathrm{K}, \mathrm{Yu}$ J. Endovascular treatments for distal posterior cerebral artery aneurysms. Turk Neurosurg. (2012) 22:1417. doi: 10.5137/1019-5149.JTN.4079-11.0

93. Signorelli F, Gory B, Pelissou-Guyotat I, Guyotat J, Riva R, Dailler $\mathrm{F}$, et al. Ruptured brain arteriovenous malformations associated with aneurysms: safety and efficacy of selective embolization in the acute phase of hemorrhage. Neuroradiology. (2014) 56:763-9. doi: 10.1007/s00234-014-1395-2

94. Reynolds MR, Arias EJ, Chatterjee AR, Chicoine MR, Cross DT. Acute rupture of a feeding artery aneurysm after embolization of a brain arteriovenous malformation. Interv Neuroradiol. (2015) 21:6139. doi: 10.1177/1591019915591740

95. Hou K, Xu K, Chen X, Ji T, Guo Y, Yu J. Targeted endovascular treatment for ruptured brain arteriovenous malformations. Neurosurg Rev. (2020) 43:1509-18. doi: 10.1007/s10143-019-01205-1

96. Wu Q, Zhang XS, Wang HD, Zhang QR, Wen LL, Hang CH, et al. Onyx embolization for tentorial dural arteriovenous fistula with pial arterial supply: case series and analysis of complications. World Neurosurg. (2016) 92:58-64. doi: 10.1016/j.wneu.2016.04.033

97. Sato K, Matsumoto $\mathrm{Y}$, Endo $\mathrm{H}$, Tominaga $\mathrm{T}$, A. hemorrhagic complication after Onyx embolization of a tentorial dural arteriovenous fistula: A caution about subdural extension with pial arterial supply. Interv Neuroradiol. (2017) 23:307-12. doi: 10.1177/159101991769 4839

98. Elia C, Minasian T, Noufal M, Chhabra V. Pial-Dural intracranial arteriovenous fistula with flow-associated aneurysmal rupture-case report with review of literature and proposal on the mechanism of hemorrhage and treatment options. World Neurosurg.

(2017) 105:1040e15-e19. doi: 10.1016/j.wneu.2017.06.152

99. Bogason ET, Patel AS, Cockroft KM. Endovascular embolization by parent artery reconstruction of a symptomatic fusiform posterior cerebral artery aneurysm using Onyx HD-500: a neurointerventional report. $J$ Neuroimaging. (2013) 23:518-22. doi: 10.1111/j.1552-6569.2012.00783.x

100. Brassel F, Rademaker J, Haupt C, Becker H. Intravascular stent placement for a fusiform aneurysm of the posterior cerebral artery: case report. Eur Radiol. (2001) 11:1250-3. doi: 10.1007/s003300000697

101. Mazaris P, Mehta T, Hussain M, Inoa V, Singer J, Spiegel G, et al. Endovascular treatment of complex distal posterior cerebral artery aneurysms with the pipeline embolization device. World Neurosurg. (2017) 107:1043e1-e5. doi: 10.1016/j.wneu.2017.04.037

102. Primiani CT, Ren Z, Kan P, Hanel R, Pereira VM, Lui WM, et al. A2, M2, P2 aneurysms and beyond: results of treatment with pipeline embolization device in 65 patients. J Neurointerv Surg. (2019) 11:9037. doi: 10.1136/neurintsurg-2018-014631

103. MacLean MA, Huynh TJ, Schmidt MH, Pereira VM, Weeks A. Competitive flow diversion of multiple P1 aneurysms: proposed classification. BMJ Case Rep. (2020) 13:e015581. doi: 10.1136/bcr-2019-015581

104. Vakharia K, Munich SA, Waqas M, Setlur Nagesh SV, Levy EI. Deployment of distal posterior cerebral artery flow diverter in tortuous anatomy. Neurosurg Focus. (2019) 46:V9. doi: 10.3171/2019.1.FocusVid.18481

105. Sturiale CL, De Waure C, Della Pepa GM, Calabro GE, Albanese A, D'Argento F, et al. Endovascular treatment of the posterior cerebral artery aneurysms: single-center experience and a systematic review. World Neurosurg. (2016) 91:154-62. doi: 10.1016/j.wneu.2016.03.083

106. Cunegatto-Braga M, Hogan B, Aguilar-Salinas P, Beier AD, Hanel RA. Pipeline embolization device flow diversion for a dissecting ruptured posterior cerebral artery aneurysm in a pediatric patient. World Neurosurg. (2018) 117:255-60. doi: 10.1016/j.wneu.2018.06.031

107. Kilburg C, Taussky P, Kalani MY, Park MS. Novel use of flow diversion for the treatment of aneurysms associated with arteriovenous malformations. Neurosurg Focus. (2017) 42:E7. doi: 10.3171/2017.2.FOCUS1755

108. Beaty NB, Campos JK, Colby GP, Lin LM, Bender MT, Xu R, et al. Pipeline flex embolization of flow-related aneurysms associated with arteriovenous malformations: a case report. Interv Neurol. (2018) 7:16470. doi: $10.1159 / 000484986$

109. Piao J, Luan T, Wang Y, Yu J. Imaging characteristics and endovascular treatment strategy for cerebellar arteriovenous malformations. Med Int. (2021) 1:5. doi: 10.3892/mi.2021.6

110. Wallace AN, Grossberg JA, Almandoz JED, Kamran M, Roy AK, Kayan $\mathrm{Y}$, et al. Endovascular treatment of posterior cerebral artery aneurysms with flow diversion: case series and systematic review. Neurosurgery. (2018) 83:790-9. doi: 10.1093/neuros/nyx561

Conflict of Interest: The authors declare that the research was conducted in the absence of any commercial or financial relationships that could be construed as a potential conflict of interest.

Publisher's Note: All claims expressed in this article are solely those of the authors and do not necessarily represent those of their affiliated organizations, or those of the publisher, the editors and the reviewers. Any product that may be evaluated in this article, or claim that may be made by its manufacturer, is not guaranteed or endorsed by the publisher.

Copyright (c) $2022 \mathrm{Hou}, \mathrm{Lv}$ and Yu. This is an open-access article distributed under the terms of the Creative Commons Attribution License (CC BY). The use, distribution or reproduction in other forums is permitted, provided the original author(s) and the copyright owner(s) are credited and that the original publication in this journal is cited, in accordance with accepted academic practice. No use, distribution or reproduction is permitted which does not comply with these terms. 